\title{
An upscaled extraction protocol for Tasmannia lanceolata (Poir.) A.C. Sm.: Anti-bacterial, anti-Giardial and anticancer activity
}

\author{
Lou Vallette ${ }^{1,2}$, Camille Rabadeaux ${ }^{1,2}$, Joseph Sirdaarta ${ }^{1,3}$, Craig Davis $^{4,5}$, Ian Edwin Cock ${ }^{1,3^{*}}$ \\ 'Environmental Futures Research 1 Institute, Griffith University, Brisbane, AUSTRALIA. \\ ${ }^{2}$ School of Biology, Ecole de Biologie Industrielle (EBI), Cergy, FRANCE. \\ ${ }^{3}$ School of Natural Sciences, Griffith University, Brisbane, AUSTRALIA. \\ ${ }^{4}$ Botanical Medicine Research Institute, Brisbane, AUSTRALIA. \\ Bioextracts P/L, Brisbane, AUSTRALIA.
}

\begin{abstract}
Background: Tasmannia lanceolata is an endemic Australian plant with a high anti-oxidant capacity. Liquid solvent extractions of T. lanceolata inhibit bacterial growth and block proliferation of several carcinomas and the gastrointestinal parasite Giardia duodenalis. Despite these promising therapeutic properties, methods for the rapid extraction of large quantities of $T$. lanceolata are lacking. This study aimed to develop a rapid supercritical extraction method to produce extracts which retain therapeutic propertyes and phytochemistry characteristics. Materials and Methods: T. lanceolata fruit and leaf were extracted by both solvent maceration extraction and supercritical fluid extraction (SFE). The extracts were tested for the ability to inhibit bacterial and G. duodenalis growth. Inhibition of $\mathrm{CaCo} 2$ and HeLa cancer cells was evaluated using MTS-based colorimetric cell proliferation assays. Toxicity was evaluated using an Artemia franciscana nauplii bioassay and GC-MS headspace analysis was used to evaluate phytochemical similarity between the extracts. Results: $T$. lanceolata berry and leaf SFEs displayed strong bacterial growth inhibitory activity against bacterial triggers of autoimmune inflammatory diseases, with efficacies similar to the smaller scale liquid solvent extractions. The growth inhibition of the berry SFE was particularly noteworthy against $P$. mirabilis and K. pneumoniae, with MIC values of approximately 160 and $190 \mu \mathrm{g} / \mathrm{mL}$, respectively. The berry and leaf SFE extracts also had similar antiproliferative potencies against $G$. duodenalis (492 and $375 \mu \mathrm{g} / \mathrm{mL}$, respectively),
\end{abstract}

CaCo2 (4133 and $3347 \mu \mathrm{g} / \mathrm{mL}$, respectively) and HeLa carcinomas (2652 and $3497 \mu \mathrm{g} / \mathrm{mL}$, respectively) to those determined for the corresponding liquid solvent extractions. GC-MS analysis of the berry SFE revealed similar terpenoid components and similar abundances to those in liquid solvent berry extraction. Furthermore, all SFEs were either non-toxic or of only low toxicity in the Artemia franciscana toxicity assay. Conclusion: The T. lanceolata SFE retained the tested therapeutic properties, were nontoxic and had similar phytochemical profiles as smaller scale liquid solvent extractions. Thus, SFE is a viable method of rapidly extracting large masses of $T$. lanceolata plant material to produce quality extracts which retain therapeutic properties.

Key words: Tasmanian pepper, Mountain pepper berry, Supercritical fluid extraction, Antibacterial activity, Giardia duodenalis, Anti-proliferative activity, Anti-cancer activity, Polygodial

\section{Correspondence:}

Ian Edwin Cock, Environmental Futures Research Institute, Griffith University, Brisbane, AUSTRALIA.

Phone no: +61 7 37357637; Fax: +61 737355282

E-mail: I.Cock@griffith.edu.au (I. E. Cock)

DOI : $10.5530 /$ pc. 2016.4 .7

\section{INTRODUCTION}

Tasmannia lanceolata (Poir.) A.C. Sm.(family Winteraceae), commonly known as Tasmanian pepper or mountain pepper berry, is a medium sized shrub which is endemic to the woodlands and cool temperate rainforests of Tasmania and the south-eastern region of the Australian mainland. As with many of the other Winteraceae species, T. lanceolata berries, leaves and bark have traditional uses as a food and as a medicinal plant. ${ }^{1}$ Australian Aborigines used T. lanceolata as a therapeutic agent to treat stomach disorders and as an emetic, as well as general usage as a tonic., ${ }^{2,3}$ Reports also exist of the use of $T$. lanceolata by the first Australians for the treatment and cure of skin disorders, venereal diseases, colic, stomach ache and as a quinine substitute. ${ }^{2}$ Furthermore, recent studies have reported an exceptionally high antioxidant capacity for T. lanceolata leaves and berries. ${ }^{4-6}$ Indeed, total ferric reducing antioxidant powers (FRAP) and DPPH reduction activities of both the T. lanceolata leaf and berry extracts were reported to be substantially higher than those determined for a blueberry control.

Based on its high antioxidant capacity, the medicinal potential of T. lanceolata has received much recent attention (Table 1). T. lanceolata leaf and berry extracts have been reported to have a wide variety of bioactivities which would confer therapeutic potential. The bacterial growth inhibitory activity of $T$. lanceolata has been particularly well reported. T. lanceolata leaf and berry extracts inhibit the growth of a broad panel of bacteria which cause food spoilage and/or cause gastrointestinal distress, diarrhoea and dysentery. ${ }^{7}$ That study reported potent growth inhibitory activity, with MIC values generally $<1000 \mu \mathrm{g} / \mathrm{mL}$. Indeed, MIC values as low as $5 \mu \mathrm{g} / \mathrm{mL}$ were determined against some bacterial species. Both the leaf and berry were potent growth inhibitors and the growth of both Gram positive and Gram negative bacteria were inhibited. Furthermore, both mesophilic and psychrotropic bacteria were affected by the T. lanceolata extracts, as were spore forming bacteria. The extracts were similarly potent inhibitors of the growth of bacteria associated with skin diseases (Staphylococcus aureus, Staphylococcus epidermidis, Streptococcus pyogenes). ${ }^{7}$ T. lanceolata extracts have even been reported to be effective inhibitors of the growth of the bacteria which cause anthrax (Bacillus anthricis) ${ }^{8}$ and gas gangrene (Clostridium perfringens). ${ }^{9}$ Both of these bacteria are endospore formers and are generally considered to be difficult to treat and decontaminate.

The potential of T. lanceolata leaf extract in treating inflammation has also been reported. ${ }^{10}$ That study reported that exposure of RAW264.7 murine macrophages to $T$. lanceolata leaf extract induces a reduction in levels of pro-inflammatory enzymes, COX-2 and iNOS, and thus a reduction in inflammation. Other recent studies have also highlighted the potential of $T$. lanceolata extracts in inhibiting the initiating events of selected autoimmune inflammatory diseases and thus their potential in the prevention and treatment of rheumatoid arthritis, ankylosing 
Table 1: Selected disease models and the drug targets that $T$. lanceolata extracts have been studied against.

\begin{tabular}{|c|c|c|c|c|}
\hline Disease & Target/Test System & Plant Product Tested & $\begin{array}{l}\text { Comments/Phytocompounds/ } \\
\text { Mechanisms }\end{array}$ & References \\
\hline Chronic oxidative disease & $\begin{array}{l}\text { Various antioxidant enzymes: Oxygen } \\
\text { radical scavenging, ferric radical } \\
\text { reducing antioxidant power, TEAC } \\
\text { evaluation and ABTS reduction }\end{array}$ & Solvent extractions & $\begin{array}{c}\text { Ascorbic acid, anthocyanins, } \\
\text { chlorogenic acid, caffeic acid, rutin, } \\
\text { quercetin }\end{array}$ & $4-6$ \\
\hline $\begin{array}{l}\text { Food poisoning, } \\
\text { diarrhoea, dysentry }\end{array}$ & $\begin{array}{l}\text { A broad panel of bacterial species } \\
\text { associated with food spoilage } \\
\text { (including mesotrophs and } \\
\text { psyschrotrophs), food poisoning, } \\
\text { diarrhoea and dysentery. }\end{array}$ & $\begin{array}{c}\text { Solvent extractions of } \\
\text { peppercorn, berry and leaf }\end{array}$ & $\begin{array}{l}\text { Polyphenolic compounds, flavonoids, } \\
\text { saponins, terpenoids }\end{array}$ & 7,9 \\
\hline Skin diseases & $\begin{array}{l}\text { Staphylococcus aureus, Staphylococcus } \\
\text { epidermidis, Streptococcus pyogenes }\end{array}$ & $\begin{array}{l}\text { Solvent extractions of } \\
\text { peppercorn, berry and leaf }\end{array}$ & $\begin{array}{l}\text { Polyphenolic compounds, flavonoids, } \\
\text { saponins, terpenoids }\end{array}$ & 7 \\
\hline Inflammation & $\begin{array}{c}\text { RAW264.7 murine macrophages, COX- } \\
\text { 1, COX-2, iNOS, PGE2 }\end{array}$ & Leaf solvent extractions & $\begin{array}{l}\text { Leaf extracts induced a reduction in } \\
\text { levels of pro-inflammatory enzymes, } \\
\text { COX-2, iNOS. }\end{array}$ & 10 \\
\hline Cancer & $\begin{array}{l}\text { HepG2 hepatocarcinoma cells, HT-29 } \\
\text { colon carcinoma cells, AGS stomach } \\
\text { carcinoma cells, BL13 bladder } \\
\text { carcinoma cells were analysed for } \\
\text { antiproliferative activity in an MTS } \\
\text { based assay. }\end{array}$ & Leaf solvent extractions & $\begin{array}{c}\text { Exposure to the high antioxidant } \\
\text { extracts induced a significant increase } \\
\text { in apoptosis in HepG2 cells and blocked } \\
\text { proliferation in all other carcinoma cell } \\
\text { lines }\end{array}$ & 15 \\
\hline Giardiasis & Giardia duodenalis & $\begin{array}{l}\text { Solvent extractions of berry } \\
\text { and leaf }\end{array}$ & $\begin{array}{l}\text { Stilbenes including combretastatins, } \\
\text { multiple tannins, monoterpenoids, } \\
\text { sesquiteriterpenoids (polygodial was } \\
\text { highlighted) }\end{array}$ & 14 \\
\hline Gas gangrene & Clostridium perfringens & $\begin{array}{l}\text { Solvent extractions of berry } \\
\text { and leaf }\end{array}$ & $\begin{array}{l}\text { Polygodial, cineole, linalool, terpineol, } \\
\text { carophyllene oxide }\end{array}$ & 9 \\
\hline
\end{tabular}

spondylitis and multiple sclerosis. ${ }^{7,11-13}$ Thus, it is likely that T. lanceolata extracts have pluripotent effects against inflammation and inflammatory diseases and thus they may be particularly useful therapeutic agents against these diseases.

The inhibitory properties of T. lanceolata extracts against the growth of several eukaryotic cells have also been reported. Berry and leaf T. lanceolata extractions are potent inhibitors of Giardia duodenalis growth ${ }^{14}$ and thus have potential in the treatment of giardiasis. Furthermore, leaf extracts have anti-cancer activity against a panel of carcinoma cell lines. ${ }^{15}$ That study examined the effect of T. lanceolata leaf extract on HepG2 hepatocarcinoma cells, HT-29 colon carcinoma cells, AGS stomach carcinoma cells and BL13 bladder carcinoma cell lines. A significant increase in apoptosis was reported in HepG2 cells, whilst the leaf extract blocked proliferation in all other carcinoma cell lines. Whilst much more work is required to further elucidate the anticancer mechanisms and the bioactive phytocompounds involved, the study did indicate very good anti-cancer potential for T. lanceolata leaves.
Several recent reports have examined the phytochemical composition of T. lanceolata extracts. ${ }^{8,9,11}$ These phytochemical evaluations have utilised LC-MS techniques to examine polar and mid-polarity compounds in leaf and berry extracts. ${ }^{11}$ Similarly, the lower polarity compounds have been detected and identified using GC-MS techniques. ${ }^{8,9}$ Irrespective of the technique used, a common feature of T. lanceolata composition is the high abundance of the sesquiterpenoid polygodial (Figure 1a). Indeed, some studies report polygodial levels as high as may account for nearly $40 \%$ of some T. lanceolata preparations. ${ }^{16}$ Further terpenoids including cineole (Figure 1b), eugenol (Figure 1c), linalool (Figure 1d) and terpineol (Figure 1e) have also been reported in relative abundance in T. lanceolata extracts. ${ }^{8,9,16}$

Whilst conventional laboratory extraction has been useful in initial studies for screening T. lanceolata berries and leaves for therapeutic properties, upscaling the extraction to produce commercially relevant levels would use large amounts of expensive solvent and be time consuming to remove the solvents by drying. Furthermore, there are very real environmental pollution concerns associated with large scale usage of organic 


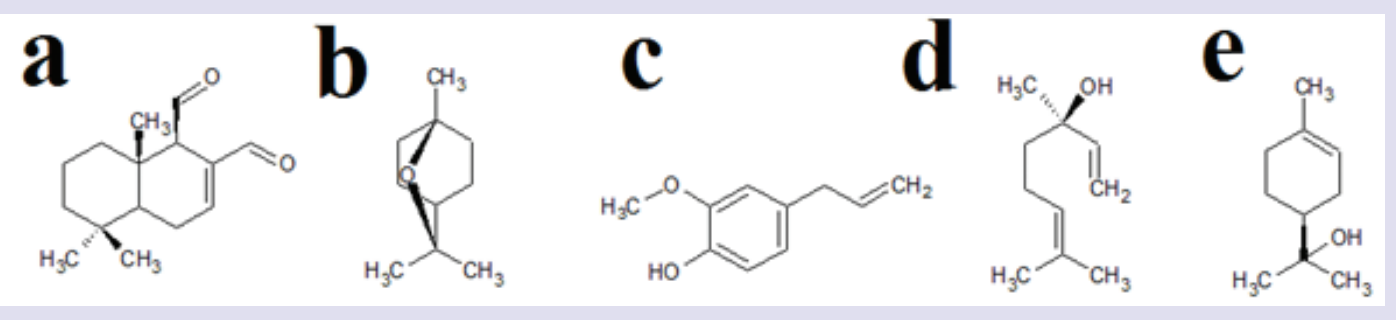

Figure 1: Chemical structures of selected terpenoid molecules identified in T. lanceolata berry extracts:(a) polygodial, (b) cineole, (c)eugenol, (d) linalool, (e) terpineol.

solvents. Up-scaled extraction protocols which provide a high yield of T. lanceolata phytochemicals are therefore of considerable interest. However, the larger scale extraction procedure would need to produce extracts with similar phytochemical profiles and therapeutic properties as those reported in the laboratory scale pilot studies. Supercritical fluid extraction (SFE) offers a number of advantages compared to conventional liquid extraction for larger scale extract preparation. Significantly less solvent is required, extraction is significantly more rapid than for extraction with an organic solvent and the properties of the supercritical fluid can be readily altered by varying the temperature and pressure, allowing for greater selectivity in extraction. Thus, SFE is ideally suited to the preparation of larger scale extract preparations.

In this study, we describe a preparative scale extraction of $T$. lanceolata berry, leaf and stem material using a SFE method which results in considerably higher extract yields at a reasonable cost. Furthermore, the therapeutic potential of these upscaled extractions was compared to the properties of the laboratory scale extractions by comparing their ability to inhibit the growth of selected bacteria associated with selected autoimmune inflammatory diseases and the growth of the gastrointestinal parasite Giardia duodenalis. The anti-cancer activity of T. lanceolata extracts was also evaluated against 2 cancer cell lines and the toxicity was determined to evaluate their usefulness as medicinal agents. Furthermore, the phytochemistries of the most promising solvent and supercritical extracts were compared by GC-MS headspace analysis targeting several marker compounds.

\section{MATERIALS AND METHODS}

\section{Laboratory scale extraction}

T. lanceolata leaf and berry were obtained from Diemen Pepper in Tasmania as a dried product. The dried pieces were subsequently ground into a coarse powder. The powdered plant material was extracted by standardised solvent extraction methods. ${ }^{7,11}$ Briefly, an amount of $1 \mathrm{~g}$ of powdered plant material was weighed into each of five tubes and five different extracts were prepared by adding $50 \mathrm{~mL}$ of methanol, water, ethyl acetate, chloroform, or hexane, respectively. Extraction in each solvent was undertaken for $24 \mathrm{hrs}$ at $4^{\circ} \mathrm{C}$ with gentle shaking. All solvents were obtained from Ajax, Australia and were AR grade. The extracts were filtered through filter paper (Whatman No. 54) under vacuum, followed by drying by centrifugal evaporation in an Eppendorf concentrator 5301. The resultant dry extract was weighed and redissolved in $10 \mathrm{~mL}$ deionised water (containing 1\% DMSO).

\section{Sub-critical extraction of Tasmannia lanceolata with dimethyl ether (DME).}

The ground Tasmanian pepper samples (berry or leaves) were packed into the biomass chamber of the extraction system. The system was sealed and evacuated before the plant material in the biomass chamber was covered with compressed solvent (dimethyl ether). The compressed gas was cycled repeatedly across the plant material for $20 \mathrm{~min}$. Subcritical DME extraction was carried out at room temperature and at a pressure of $500 \mathrm{MPa}$. The solvent was recycled and stored in a solvent reservoir. After the compressed gas (the dimethyl ether) had been removed, the material that had been extracted from the plant biomass was collected in a separate vessel.

\section{Qualitative phytochemical studies}

Phytochemical analysis of the T. lanceolata extracts for the presence of saponins, phenolic compounds, flavonoids, polysteroids, triterpenoids, cardiac glycosides, anthraquinones, tannins and alkaloids was conducted by previously described assays. ${ }^{17-19}$

\section{Antibacterial screening}

\section{Test microorganisms}

All media was supplied by Oxoid Ltd. Australia. Reference strains of Acinitobacter baylyi (ATCC33304), Klebsiella pneumoniae (ATCC31488), Proteus mirabilis (ATCC21721), Proteus vulgaris (ATCC21719) and Pseudomonas aeruginosa (ATCC39324) were purchased from American Tissue Culture Collection, USA. All other clinical microbial strains were obtained from the School of Natural Sciences teaching laboratory, Griffith University. All stock cultures were subcultured and maintained in nutrient broth at $4^{\circ} \mathrm{C}$.

\section{Evaluation of antimicrobial activity}

Antimicrobial activity of all plant extracts was determined using a modified disc diffusion method. ${ }^{20-22}$ Briefly, $100 \mu \mathrm{L}$ of the test bacteria were grown in $10 \mathrm{~mL}$ of fresh nutrient broth until they reached a count of approximately $10^{8}$ cells $/ \mathrm{mL}$ as determined by direct microscopic determination. One hundred microliters of microbial suspension was subsequently spread onto the agar plates. The extracts were applied onto $5 \mathrm{~mm}$ sterilised filter paper discs. Discs were impregnated with $10 \mu \mathrm{L}$ of the test sample, allowed to dry and placed onto inoculated plates. The plates were allowed to stand at $4^{\circ} \mathrm{C}$ for $2 \mathrm{hrs}$ before incubation with the test microbial agents. The plates were then incubated at $30^{\circ} \mathrm{C}$ for $24 \mathrm{hrs}$ and the diameters of the inhibition zones were measured in millimetres. All measurements were to the closest whole millimetre. Each antimicrobial assay was performed in at least triplicate and mean values were determined. Standard discs of ampicillin $(10 \mu \mathrm{g})$ were obtained from Oxoid Ltd. Australia and served as positive controls. Filter discs impregnated with $10 \mu \mathrm{L}$ of distilled water were used as negative controls.

\section{Minimum inhibitory concentration (MIC) determination}

The minimum inhibitory concentration (MIC) of the $T$. lanceolata extracts were determined by the disc diffusion method across a range of doses. ${ }^{23}$ The plant extracts were diluted in deionised water across a 
concentration range of $5 \mathrm{mg} / \mathrm{mL}$ to $0.1 \mathrm{mg} / \mathrm{mL}$. Discs were impregnated with $10 \mu \mathrm{L}$ of the test dilutions, allowed to dry and placed onto inoculated plates. The assay was performed as outlined above and graphs of the zone of inhibition versus concentration were plotted for each extract. Linear regression was used to calculate the MIC values.

\section{Inhibitory bioactivity against Giardia duodenalis trophozoites}

\section{Parasite culture}

The reference Giardia duodenalis trophozoite strain (ATTC203333) used in this study was purchased from American Tissue Culture Collection, USA. G. duodenalis tropozoites were maintained and subcultured anaerobically at $37^{\circ} \mathrm{C}$ in TYI-S-33 growth media supplemented with $1 \%$ bovine bile (Sigma), 10\% Serum Supreme (Cambrex Bioproducts) and $200 \mathrm{IU} / \mathrm{mL}$ penicillin/200 $\mu \mathrm{g} / \mathrm{mL}$ streptomycin (Invitrogen, USA). Confluent mid log phase cultures were passaged every 2 days by chilling the cultures on ice for a minimum of $10 \mathrm{~min}$, followed by vortexing to dislodge the adherent trophozoites from the walls of the culture vessel. Fresh culture media $(5 \mathrm{~mL})$ was seeded with approximately $1 \times 10^{5}$ trophozoites for each passage.

\section{Evaluation of anti-Giardial activity}

Anti-Giardial activity of the T. lanceolata extracts was assessed by direct enumeration of parasite numbers in the presence or absence of extract. $^{14,22}$ For each test, aliquots of the trophozoite suspension $(70 \mu \mathrm{L})$ containing approximately $1 \times 10^{5}$ trophozoites were added to the wells of a 96 well plate. A volume of $30 \mu \mathrm{L}$ of the test extracts or the vehicle solvent or culture media (for the negative controls) was added to individual wells and the plates were incubated anaerobically at $37^{\circ} \mathrm{C}$ for $8 \mathrm{hrs}$ in a humidified anaerobic atmosphere. Following the $8 \mathrm{~h}$ incubation, all tubes were placed on ice for a minimum of $10 \mathrm{~min}$, followed by vortexing to dislodge the adherent trophozoites from the walls of the culture vessel. The suspensions were mounted onto a Neubauer haemocytometer (Weber, UK) and the total trophozoites per $\mathrm{mL}$ were determined. The anti-proliferative activity of the test extracts was determined and expressed as a $\%$ of the untreated control trophozoites per ml.

\section{Determination of $I C_{50}$ values against Giardial trophozoites}

For $\mathrm{IC}_{50}$ determinations, the plant extracts were tested by the direct enumeration method across a range of concentrations. The assays were performed as outlined above and graphs of the zone of inhibition versus concentration were plotted for each extract. Linear regression was used to calculate the $\mathrm{IC}_{50}$ values.

\section{Screen for anti-cancer bioactivity Cancer cell lines}

The $\mathrm{CaCo} 2$ and HeLa carcinoma cell lines used in this study were obtained from American Type Culture Collection (Rockville, USA). The cells were cultured in Roswell Park Memorial Institute (RPMI) 1640 medium (Life Technologies), supplemented with $20 \mathrm{mM}$ HEPES, $10 \mathrm{mM}$ sodium bicarbonate, $50 \mu \mathrm{g} / \mathrm{ml}$ streptomycin, $50 \mathrm{IU} / \mathrm{mL}$ penicillin, $2 \mathrm{mM}$ glutamine and $10 \%$ foetal calf serum (Life Technologies). The cells were maintained as monolayers in $75 \mathrm{~mL}$ flasks at $37^{\circ} \mathrm{C}, 5 \% \mathrm{CO}_{2}$ in a humidified atmosphere until approximately $80 \%$ confluent.

\section{Evaluation of cancer cell anti-proliferative activity}

Evaluation of the antiproliferative activity of the T. lanceolata extracts was as previously described. ${ }^{4,21}$ Briefly, $1 \mathrm{~mL}$ of trypsin (Sigma) was added to the culture flasks and incubated at $37^{\circ} \mathrm{C}, 5 \% \mathrm{CO}_{2}$ for $15 \mathrm{~min}$ to dislodge the cancer cells. The cell suspensions were then transferred to a $10 \mathrm{~mL}$ centrifuge tube and sedimented by centrifugation. The supernatant was discarded and the cells were resuspended in $9 \mathrm{~mL}$ of fresh media. Aliquots of the resuspended cells $(70 \mu \mathrm{L}$, containing approximately 5000 cells) were added to the wells of a 96 well plate. A volume of $30 \mu \mathrm{L}$ of the test extracts or cell media (for the negative control) was added to individual wells and the plates were incubated at $37^{\circ} \mathrm{C}, 5 \% \mathrm{CO}_{2}$ for $12 \mathrm{hrs} \mathrm{in} \mathrm{a}$ humidified atmosphere. A volume of $20 \mu \mathrm{L}$ of Cell Titre 96 Aqueous One solution (Promega) was subsequently added to each well and the plates were incubated for a further $3 \mathrm{hrs}$. Absorbances were recorded at $490 \mathrm{~nm}$ using a Molecular Devices, Spectra Max M3 plate reader. All tests were performed in at least triplicate and triplicate controls were included on each plate. The anti-proliferative activity of each test was calculated as a percentage of the negative control using the following formula:

$$
\text { Proliferation }(\% \text { untreated control })=\left(\mathrm{A}_{\mathrm{ct}} / \mathrm{A}_{\mathrm{cc}}\right) \times 100
$$

$\mathrm{A}_{\mathrm{ct}}$ is the corrected absorbance for the test extract (calculated by subtracting the absorbance of the test extract in media without cells from the extract cell test combination) and $\mathrm{A}_{\mathrm{cc}}$ is the corrected untreated control (calculated by subtracting the absorbance of the untreated control in media without cells from the untreated cell media combination).

\section{Determination of $\mathrm{IC}_{50}$ values against $\mathrm{CaCo} 2$ and HeLa carcinoma cells}

For $\mathrm{IC}_{50}$ determinations, the plant extracts were tested by the Cell Titre 96 colourimetric method across a range of concentrations. The assays were performed as outlined above and graphs of the zone of inhibition versus concentration were plotted for each extract. Linear regression was used to calculate the $\mathrm{IC}_{50}$ values.

\section{Toxicity screening \\ Reference toxins for biological screening}

Potassium dichromate $\left(\mathrm{K}_{2} \mathrm{Cr}_{2} \mathrm{O}_{7}\right)$ (AR grade, Chem-Supply, Australia) was prepared as a $2 \mathrm{mg} / \mathrm{mL}$ solution in distilled water and was serially diluted in synthetic seawater for use in the A. franciscana nauplii bioassay.

\section{Artemia franciscana nauplii toxicity screening}

Toxicity was tested using a modified Artemia franciscana nauplii lethality assay. ${ }^{24-26}$ Briefly, A. franciscana cysts were obtained from North American Brine Shrimp, LLC, USA (harvested from the Great Salt Lake, Utah). Synthetic seawater was prepared using Reef Salt, AZOO Co., USA. Seawater solutions at $34 \mathrm{~g} / \mathrm{L}$ distilled water were prepared prior to use. An amount of $1 \mathrm{~g}$ of $A$. franciscana cysts were incubated in $500 \mathrm{~mL}$ synthetic seawater under artificial light at $25^{\circ} \mathrm{C}, 2000$ Lux with continuous aeration. Hatching commenced within 16-18 h of incubation. Newly hatched A. franciscana (nauplii) were used within $10 \mathrm{~h}$ of hatching. Nauplii were separated from the shells and remaining cysts and were concentrated to a suitable density by placing an artificial light at one end of their incubation vessel and the nauplii-rich water closest to the light was removed for biological assays. The extracts and positive control were also serially diluted in artificial seawater for $\mathrm{LC}_{50}$ determination. A volume of $400 \mu \mathrm{L}$ of seawater containing approximately 46 (mean $45.8, \mathrm{n}=125$, SD 12.3) nauplii were added to wells of a 48 -well plate and immediately used for bioassay. The plant extracts were diluted to $4 \mathrm{mg} / \mathrm{mL}$ in seawater for toxicity testing, resulting in a $2 \mathrm{mg} / \mathrm{mL}$ concentration in the bioassay. A volume of $400 \mu \mathrm{L}$ of diluted plant extract and the reference toxins were transferred to the wells and incubated at $25 \pm 1^{\circ} \mathrm{C}$ under artificial light (1000 Lux). A negative control ( $400 \mu \mathrm{L}$ seawater) was run in at least triplicate for each plate. All treatments were performed in at least triplicate. The wells were checked at regular intervals and the number of dead counted. The nauplii were considered moribund if no movement of the appendages was 


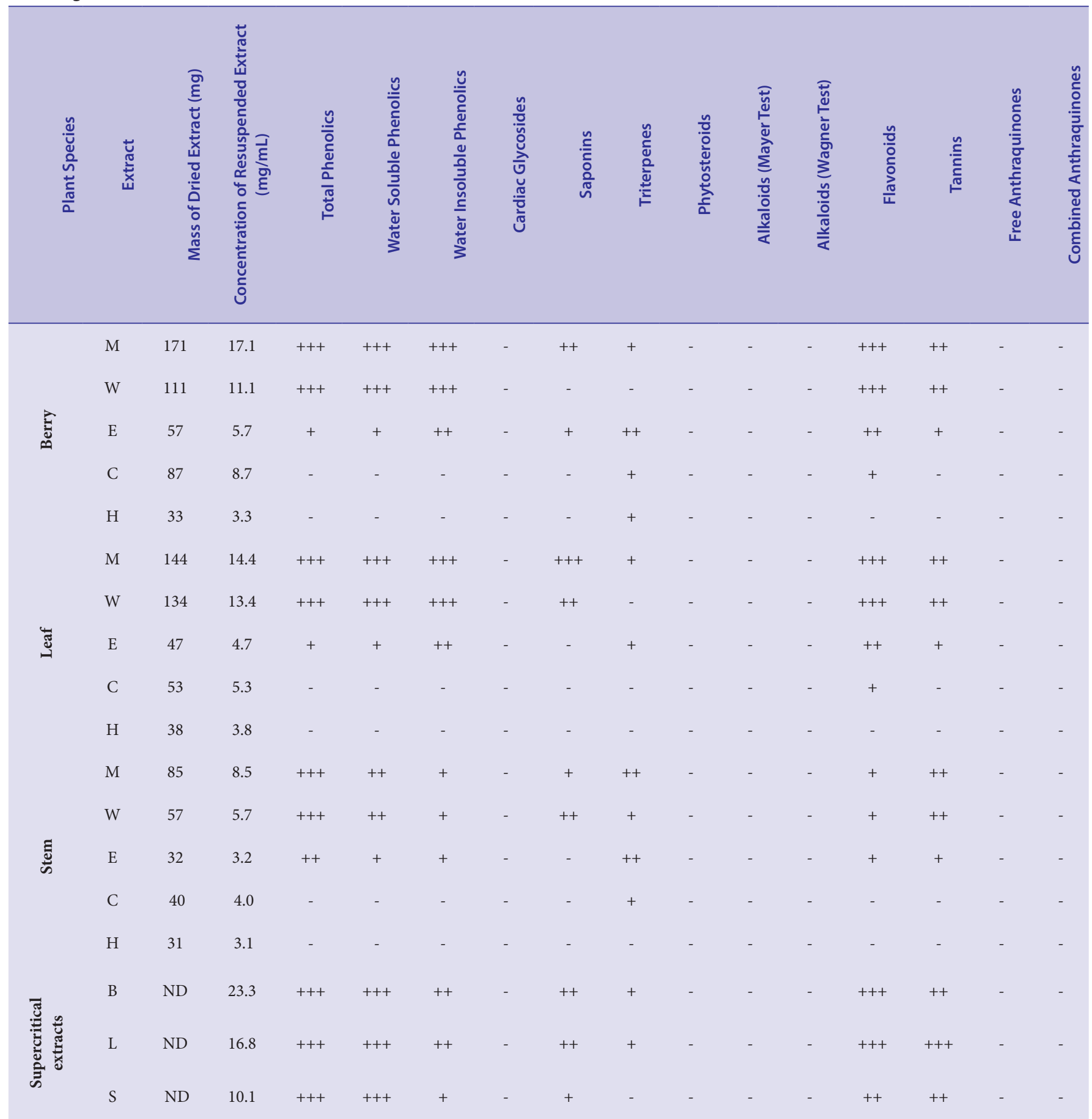

+++ indicates a large response; ++ indicates a moderate response; + indicates a minor response; - indicates no response in the assay. $\mathrm{M}=\mathrm{methanolic}$ extract; $\mathrm{W}=$ aqueous extract; $\mathrm{E}=$ =ethyl acetate extract; $\mathrm{C}=$ chloroform extract; $\mathrm{H}=$ hexane extract; $\mathrm{B}=$ berry; $\mathrm{L}=$ leaf; $\mathrm{S}=$ stem; $\mathrm{ND}=$ not determined.

observed within $10 \mathrm{sec}$. After $48 \mathrm{~h}$, all nauplii were sacrificed and counted to determine the total number per well. The $\mathrm{LC}_{50}$ with $95 \%$ confidence limits for each treatment was calculated using probit analysis.

\section{Non-targeted GC-MS head space analysis}

Separation and quantification of phytochemical components were performed using a Shimadzu GC-2010 plus (USA) linked to a Shimadzu MS TQ8040 (USA) mass selective detector system as previously described.$^{27}$ Briefly, the system was equipped with a Shimadzu auto-sampler AOC-5000 plus (USA) fitted with a solid phase micro-extraction fibre (SPME) handling system utilising a Supelco (USA) divinyl benzene/ carbowax/polydimethylsiloxane (DVB/CAR/PDMS). Chromatographic separation was accomplished using a 5\% pheny $1,95 \%$ dimethylpolysiloxane $(30 \mathrm{~m} \times 0.25 \mathrm{~mm}$ id $\times 0.25 \mu \mathrm{m})$ capillary column (Restek USA). Helium (99.999\%) was employed as a carrier gas at a flow rate of 0.79 $\mathrm{mL} / \mathrm{min}$. The injector temperature was set at $230^{\circ} \mathrm{C}$. Sampling utilised a 
SPME cycle which consisted of an agitation phase at $500 \mathrm{rpm}$ for a period of $5 \mathrm{sec}$. The fibre was exposed to the sample for $10 \mathrm{~min}$ to allow for absorption and then desorbed in the injection port for $1 \mathrm{~min}$ at $250^{\circ} \mathrm{C}$. The initial column temperature was held at $30^{\circ} \mathrm{C}$ for $2 \mathrm{~min}$, increased to $140^{\circ} \mathrm{C}$ for $5 \mathrm{~min}$, then increased to $270^{\circ} \mathrm{C}$ over a period of $3 \mathrm{mins}$ and held at that temperature for the duration of the analysis. The GC-MS interface was maintained at $200^{\circ} \mathrm{C}$ with no signal acquired for a min after injection in split-less mode. The mass spectrometer was operated in the electron ionisation mode at $70 \mathrm{eV}$. The analytes were then recorded in total ion count (TIC) mode. The TIC was acquired after a min and for duration of 45 mins utilising a mass range of $45-450 \mathrm{~m} / \mathrm{z}$.

\section{Statistical analysis}

Data are expressed as the mean \pm SEM of at least three independent experiments. One way ANOVA was used to calculate statistical significance between control and treated groups with a $P$ value $<0.01$ considered to be statistically significant.

\section{RESULTS}

\section{Liquid extraction yields and qualitative phytochemical screening}

Extraction of $1 \mathrm{~g}$ of dried plant material with various solvents yielded dried plant extracts ranging from approximately $31 \mathrm{mg}$ (T. lanceolata stem hexane extract) to $171 \mathrm{mg}$ (T. lanceolata berry methanolic extract) (Table 2). Water and methanol gave the highest yields of dried extracted material for all T. lanceolata plant materials tested, whilst ethyl acetate, chloroform and hexane extracted substantially lower masses. The dried extracts were resuspended in $10 \mathrm{~mL}$ of deionised water (containing 1\% DMSO) resulting in the extract concentrations shown in Table 2. In contrast, the supercritical extractions of all T. lanceolata plant materials generally yielded higher concentration extracts (Table 2).

Phytochemical studies (Table 2) show that methanol and water extracted the widest range and largest amount of phytochemicals of the laboratory scale extractions. The aqueous and methanolic extracts both showed moderate to high levels of total phenolics (water soluble and insoluble phenolics), flavonoids and tannins. The methanolic extract also contained moderate levels of saponins. Similar classes of phytochemicals were detected in the ethyl acetate extract, albeit generally at lower levels than in the aqueous and methanolic extracts. Most of the phytochemical classes were not evident in the chloroform or hexane extracts. Indeed, these extracts only contained detectable levels of triterpenoids. The supercritical extractions displayed similar phytochemical profiles as the laboratory scale aqueous and methanolic extractions. All of the supercritical extractions contained high levels of total phenolics (particularly water-soluble phenolics), flavonoids and tannins. Moderate levels of saponins and low levels of triterpenoids were also generally detected in the supercritical berry, leaf and stem T. lanceolata extracts. Thus, qualitative phytochemical analysis indicates that the larger scale supercritical extractions contain similar classes of phytochemical as evident in the laboratory scale extractions which were prepared in the same way as extractions with previously published therapeutic properties (Table 1). ${ }^{7,11}$

\section{Antimicrobial activity}

Aliquots $(10 \mu \mathrm{L})$ of each extract were tested in the disc diffusion assay against bacterial species associated with the induction of rheumatoid arthritis (Proteus mirabilis, Figure 2a; Proteus vulgaris, Figure 2b), ankylosing spondylitis (Klebsiella pneumoniae, Figure 3), multiple sclerosis (Acinitobacter baylyi, Figure 4a; Pseudomonas aeruginosa, Figure 4b) and rheumatic fever (Streptococcus pyogenes, Figure 5). Consistent with previous studies, ${ }^{11}$ the methanolic and aqueous berry and leaf extracts were potent inhibitors of reference and clinical strains of $P$. mirabilis (Figure 2a), with zones of inhibition approximately $8-13.5 \mathrm{~mm}$. The leaf extracts were particularly potent, with zones of inhibition of $12.6 \pm 0.3$ and $12.0 \pm 1.0 \mathrm{~mm}$ for the methanolic leaf extract (against the reference and clinical strains, respectively) and $12.8 \pm 0.4$ and $13.2 \pm 0.4 \mathrm{~mm}$ for the aqueous leaf extract (against the reference and clinical strains, respectively). The aqueous and methanolic berry and leaf extracts were similarly potent growth inhibitors against $P$. vulgaris (Figure $2 \mathrm{~b}$ ). Zones of inhibition of $8.7 \pm 0.4$ and $12.8 \pm 0.4 \mathrm{~mm}$ were recorded for the methanolic berry and leaf extracts, respectively. Similarly, growth inhibition zones of 8.0 and $13.2 \pm 0.4 \mathrm{~mm}$ were seen for the aqueous berry and leaf extracts, respectively. Whilst the berry and leaf ethyl acetate extracts, as well as the aqueous and methanolic stem extracts also inhibited Proteus spp. growth, they had lower efficacy (as judged by the zone of inhibition) than evident for the corresponding methanolic and aqueous extracts.

The supercritical extracts also were good inhibitors of Proteus spp. growth. The supercritical berry extract was particularly potent, with zones of inhibition of $11.3 \pm 0.6$ and $10.6 \pm 0.6 \mathrm{~mm}$ against $P$. mirabilis (reference and clinical strains, respectively), and $9.6 \pm 0.3 \mathrm{~mm}$ against $P$. vulgaris. The leaf extract was also a good inhibitor of $P$. mirabilis growth, with inhibition zones of $8.7 \pm 0.3$ (reference strain) and $8.2 \pm 0.4 \mathrm{~mm}$ (clinical strain). The supercritical leaf extract displayed slightly better efficacy against $P$. vulgaris with a $9.3 \pm 0.6 \mathrm{~mm}$ zone of inhibition. Thus, the supercritical berry extract had similar efficacy to the small scale laboratory extraction (as judged by zone of inhibition). In contrast, the supercritical leaf extract was a less potent growth inhibitor compared with the smaller scale solvent extraction. As Proteus spp. (particularly P. mirabilis) are triggers of rheumatoid arthritis in genetically susceptible people, ${ }^{11,12}$ these extracts may be useful in the prevention and treatment of this disease.

A similar activity profile was evident for K. pneumoniae growth inhibition (Figure 3). The methanolic leaf extract was the most potent growth inhibitor, with zones of inhibition of $9.6 \pm 0.6$ (reference strain) and $8.3 \pm 0.6 \mathrm{~mm}$ (clinical strain). This compares favourably with the ampicillin control $(10 \mu \mathrm{g}$ ) which had $9.2 \pm 0.4$ (reference strain) and $8.7 \pm 0.3 \mathrm{~mm}$ (clinical strain) zones of inhibition. The aqueous leaf extract was a similarly good K. pneumoniae growth inhibitor, with $8.7 \pm 0.4$ and $8.6 \pm 0.3 \mathrm{~mm}$ zones of inhibition recorded against the reference and clinical strains, respectively. Whilst displaying smaller zones of inhibition (generally substantially $<8.0 \mathrm{~mm}$ ), the berry (methanolic, aqueous and ethyl acetate extracts) and stem (methanolic and aqueous extracts) also inhibited K. pneumoniae growth. Notably, the supercritical berry $(8.3 \pm 0.3$ and $7.5 \pm$ $0.5 \mathrm{~mm}$ against the reference and clinical strains) and leaf extracts (8.0 and $7.8 \pm 0.4 \mathrm{~mm}$ against the reference and clinical strains) had similar potency to the small scale solvent extractions. As K. pneumoniae can trigger ankylosing spondylitis in genetically susceptible individuals, ${ }^{13}$ these extracts have potential in the prevention and treatment of this disease.

The T. lanceolata extracts were also screened for growth inhibitory activity against bacterial triggers of multiple sclerosis (Acinitobacter baylyi, Figure $4 \mathrm{a}$; Pseudomonas aeruginosa, Figure $4 \mathrm{~b}){ }^{28,29}$ The methanolic and aqueous leaf extracts were the most potent $A$. baylyi growth inhibitors, with zones of inhibition ranging from 8.2-8.6 $\mathrm{mm}$ (compared to $8.6 \mathrm{~mm}$ for the $10 \mu \mathrm{g}$ ampicillin control). Although smaller inhibition zones $(7-7.8 \mathrm{~mm})$ were measured for the methanolic and aqueous berry extracts, these extracts were still deemed to be good $A$. baylyi growth inhibitors. Similarly, the supercritical berry $(7.3 \pm 0.3$ and $7.6 \pm 0.3 \mathrm{~mm}$ against the reference and clinical strains, respectively) and leaf extracts (7.0 and $7.3 \pm 0.3 \mathrm{~mm}$ against the reference and clinical strains, respectively) were also good inhibitors of $A$. baylyi growth.

The aqueous and methanolic extracts (berry and leaf) also inhibited P. aeruginosa growth (Figure $4 \mathrm{~b}$ ), albeit with relatively small zones of 


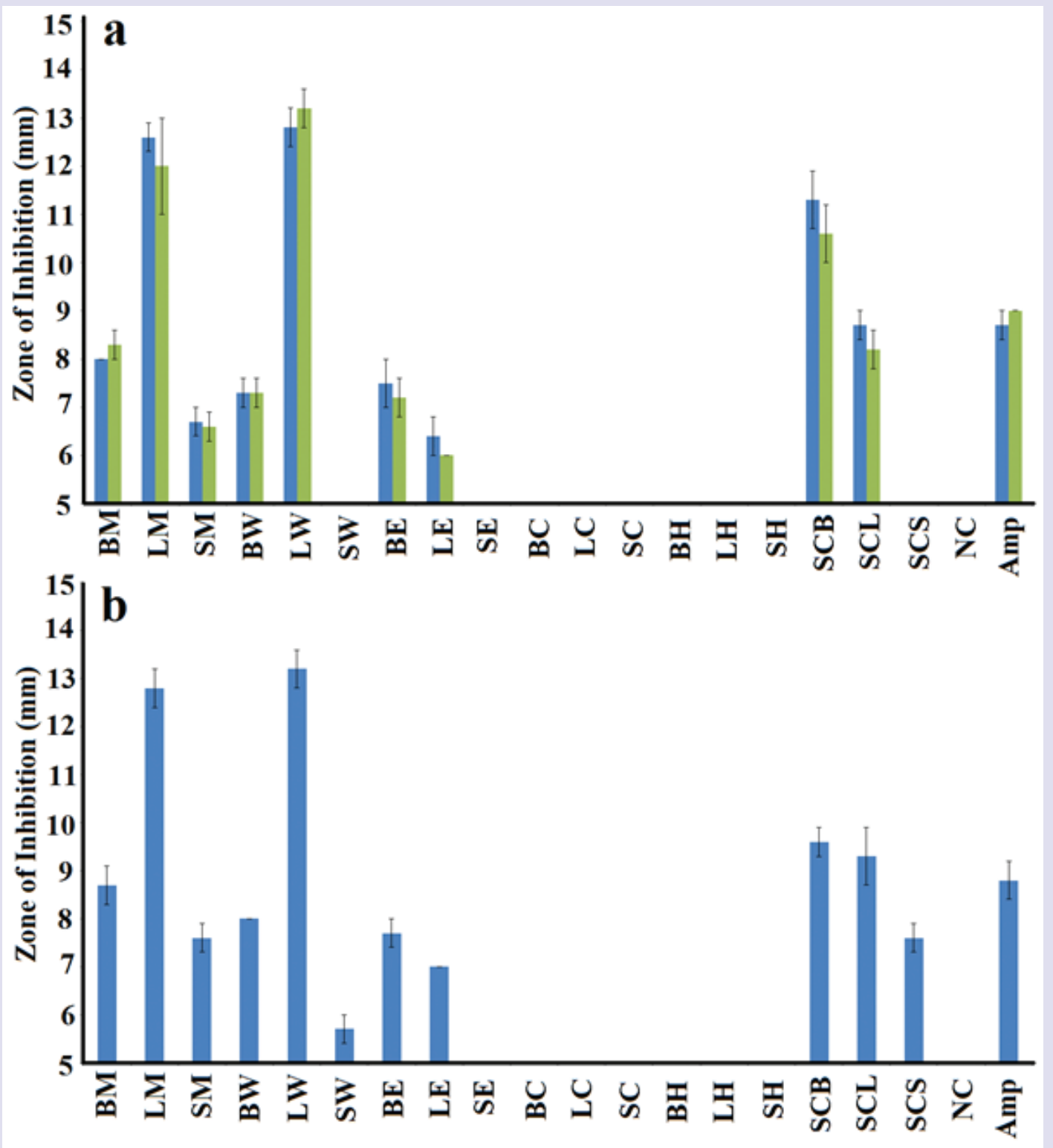

Figure 2: Antibacterial activity of $T$. lanceolata extracts measured as zones of inhibition $(\mathrm{mm})$ against a bacterial trigger of rheumatoid arthritis: (a) Proteus mirabilis, (b) Proteus vulgaris. Results are expressed as mean \pm SEM of at least triplicate determinations. Blue bars represent inhibition of the reference bacterial strain. Green bars represent inhibition of the clinical bacterial strain. $\mathrm{BM}=$ methanolic berry extract; $\mathrm{LM}=$ methanolic leaf extract; $\mathrm{SM}=$ methanolic stem extract; $\mathrm{BW}=$ aqueous berry extract; $\mathrm{LW}=\mathrm{aqueous}$ leaf extract; $\mathrm{SW}=$ aqueous stem extract; $\mathrm{BE}=$ ethyl acetate berry extract; $\mathrm{LE}=$ =thyl acetate leaf extract; $\mathrm{SE}=$ ethyl acetate stem extract; $\mathrm{BC}=$ berry chloroform extract; $\mathrm{LC}=$ leaf chloroform extract; $\mathrm{SC}=$ stem chloroform extract; $\mathrm{BH}=$ berry hexane extract; $\mathrm{LH}=$ leaf hexane extract; $\mathrm{SH}=$ stem hexane extract; $\mathrm{SCB}=$ supercritical berry extract; $\mathrm{SCL}=$ supercritical leaf extract; $\mathrm{SCS}=$ supercritical stem extract; $\mathrm{NC}=$ negative control; $\mathrm{Amp}=$ ampicillin control $(10 \mu \mathrm{g})$.

inhibition. The strongest inhibition $(6.5 \pm 0.5 \mathrm{~mm})$ was recorded for the methanolic berry extract against reference $P$. aeruginosa strain. The supercritical berry and leaf extracts had similar potencies, with inhibition zones $\leq 6.3 \mathrm{~mm}$. Whilst this inhibition is relatively poor in comparison the other bacterial species screened, it is noteworthy that both the reference and clinical $P$. aeruginosa strains are antibiotic resistant strains. Indeed, the $10 \mu \mathrm{g}$ ampicillin control used in our studies only produced $6.2 \pm 0.4$ and $5.5 \pm 0.3 \mathrm{~mm}$ zones of inhibition for the reference and clinical strains, respectively. This finding is supported by previous studies which have also reported these strains to be antibiotic resistant. ${ }^{23,27}$ Thus, despite the relatively small inhibition zones, the T. lanceolata extracts may still be useful for the inhibition of $P$. aeruginosa growth. Therefore, as both $A$. baylyi and $P$. aeruginosa can trigger multiple sclerosis in genetically susceptible individuals, ${ }^{28,29}$ these extracts have potential in the prevention and treatment of this disease.

The T. lanceolata aqueous and methanolic berry and leaf extracts were also good inhibitors of Streptococcus pyogenes growth (Figure 5). The aqueous leaf extract was the most potent growth inhibitor, with an inhibition zone of $10.6 \pm 0.4 \mathrm{~mm}$. However, unlike the inhibition reported for the other bacterial species, the berry ethyl acetate was also a very 


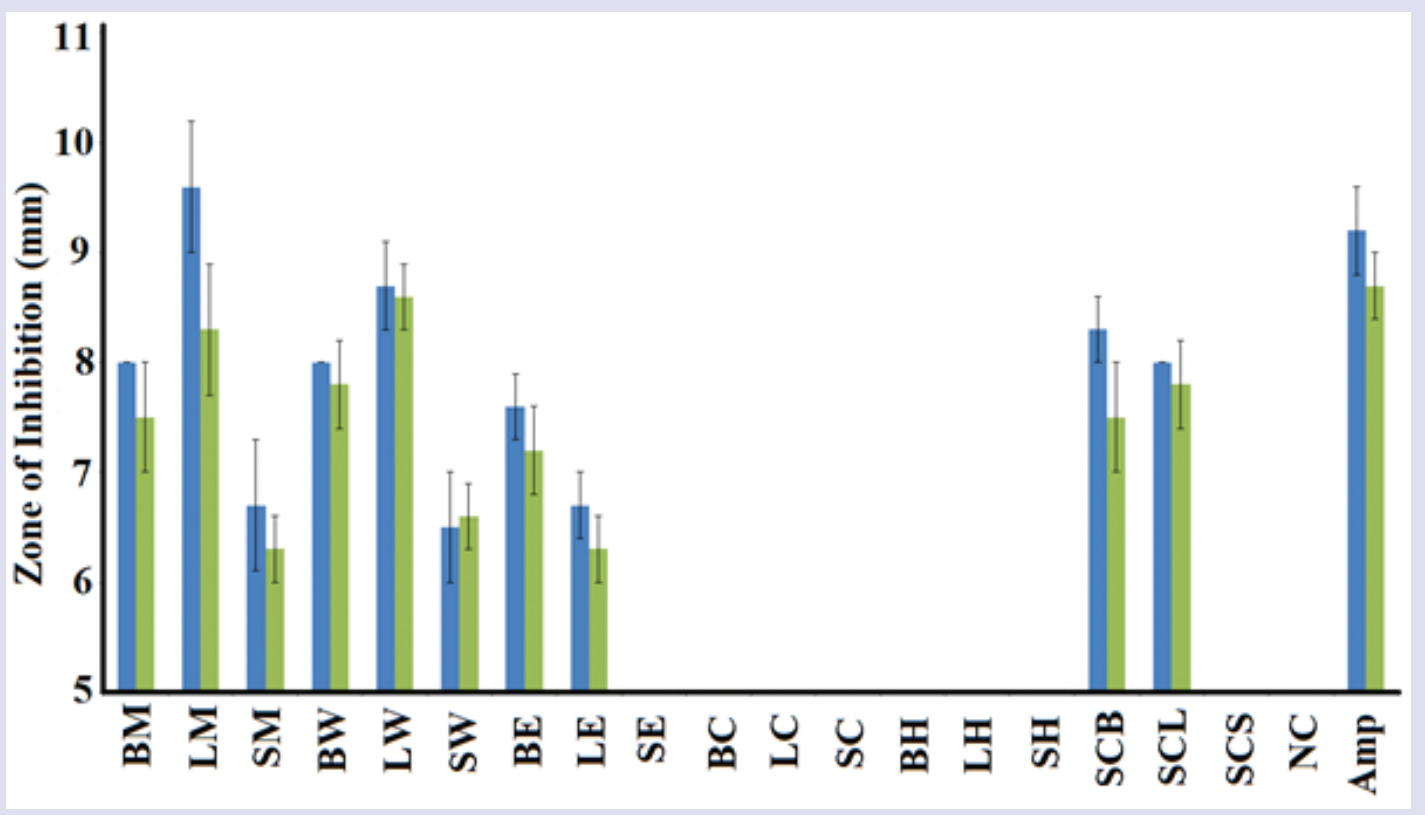

Figure 3: Antibacterial activity of $T$. lanceolata extracts measured as zones of inhibition $(\mathrm{mm})$ against a bacterial trigger of ankylosing spondylitis (Klebsiella pneumoniae). Results are expressed as mean \pm SEM of at least triplicate determinations. Blue bars represent inhibition of the reference bacterial strain. Green bars represent inhibition of the clinical bacterial strain. BM=methanolic berry extract; $\mathrm{LM}=$ methanolic leaf extract; $\mathrm{SM}=$ methanolic stem extract; $\mathrm{BW}=$ aqueous berry extract; $\mathrm{LW}=$ aqueous leaf extract; $\mathrm{SW}=$ aqueous stem extract; $\mathrm{BE}=$ ethyl acetate berry extract; $\mathrm{LE}=$ ethyl acetate leaf extract; $\mathrm{SE}=$ ethyl acetate stem extract; $\mathrm{BC}=$ berry chloroform extract; $\mathrm{LC}=$ leaf chloroform extract; $\mathrm{SC}=$ stem chloroform extract; $\mathrm{BH}=$ berry hexane extract; $\mathrm{LH}=\mathrm{leaf}$ hexane extract; $\mathrm{SH}=$ stem hexane extract; $\mathrm{SCB}=$ supercritical berry extract; $\mathrm{SCL}=$ supercritical leaf extract; $\mathrm{SCS}=$ supercritical stem extract; $\mathrm{NC}=$ negative control; $\mathrm{Amp}=$ ampicillin control $(10 \mu \mathrm{g})$.

good growth inhibitor of $S$. pyogenes $(9.8 \pm 0.4 \mathrm{~mm})$. The berry methanolic $(8.3 \pm 0.3 \mathrm{~mm})$ and aqueous extracts $(7.6 \pm 0.3 \mathrm{~mm})$, as well as the methanolic leaf extract $(7.6 \pm 0.3 \mathrm{~mm})$, were also good growth inhibitors. In comparison, the supercritical leaf extract displayed potent growth inhibitory activity $(9 \mathrm{~mm})$. The supercritical berry extract was also a relatively good $S$. pyogenes growth inhibitor, with a zone of inhibition of $7.3 \pm 0.3 \mathrm{~mm}$. S. pyogenes has been implicated in a number of diseases including rheumatic fever. Thus, the T. lanceolata extracts have potential in the prevention and treatment of these diseases.

The relative level of antimicrobial activity was further evaluated by determining the MIC values (Table 3) for each extract against the bacterial species which were shown to be susceptible by disc diffusion assays. Most of the extracts were effective at inhibiting microbial growth at low concentrations, with MIC values against the bacterial species that they inhibited often substantially $<500 \mu \mathrm{g} / \mathrm{mL}$ ( $<5 \mu \mathrm{g}$ infused into the disc), indicating the potent antimicrobial activity of these extracts. The methanolic berry extract was a particularly potent bacterial growth inhibitor, with MIC values as low as $15 \mu \mathrm{g} / \mathrm{mL}(<0.15 \mu \mathrm{g}$ infused into the disc) against $P$. mirabilis. This extract was similarly potent against $K$. pneumoniae (MIC values as low as $33 \mu \mathrm{g} / \mathrm{mL} ; 0.3 \mu \mathrm{g}$ infused into the disc), A. baylyi (MIC values as low as $280 \mu \mathrm{g} / \mathrm{mL} ; 2.8 \mu \mathrm{g}$ infused into the disc), $P$. aeruginosa (MIC values as low as $288 \mu \mathrm{g} / \mathrm{mL} ; 2.9 \mu \mathrm{g}$ infused into the disc) and S. pyogenes (MIC values of $423 \mu \mathrm{g} / \mathrm{mL} ; 4.2 \mu \mathrm{g}$ infused into the disc). These MIC values compare favourably with the inhibition of the pure ampicillin standard which was tested using $10 \mu \mathrm{g}$ per disc. The methanolic leaf, as well as the aqueous and ethyl acetate berry and leaf extracts were also good bacterial growth inhibitors, generally with MIC values $<500 \mu \mathrm{g} / \mathrm{mL}$ against most bacterial species.
The supercritical fluid berry and leaf extracts were also effective at inhibiting bacterial growth at low concentrations, with MIC values against the bacterial species that they inhibited often substantially $<300 \mu \mathrm{g} / \mathrm{mL}$ $(<3 \mu \mathrm{g}$ infused into the disc). The supercritical berry and leaf extracts were particularly potent against Proteus spp. and K. pneumoniae. Indeed, the berry and leaf extracts had MIC values of approximately $160 \mu \mathrm{g} / \mathrm{mL}$ (1.6 $\mu \mathrm{g}$ infused into the disc) and $280 \mu \mathrm{g} / \mathrm{mL}(2.8 \mu \mathrm{g}$ infused into the disc), respectively against $P$. mirabilis. In contrast, distinct differences were noted between the berry and leaf supercritical extracts against the other bacterial species. MIC values of approximately $150 \mu \mathrm{g} / \mathrm{mL}(1.5 \mu \mathrm{g}$ infused into the disc) were recorded for the supercritical berry extract against $K$. pneumoniae. In contrast, MIC values of approximately 1500 $\mu \mathrm{g} / \mathrm{mL}$ ( $15 \mu \mathrm{g}$ infused into the disc) were measured for the corresponding supercritical leaf extract. Whilst this MIC value indicates that this is still a good bacterial growth inhibitor, it is an order of magnitude less potent than the supercritical berry extract. Whilst the supercritical extracts were not as potent at inhibiting the growth of $A$. baylyi (MICs of approximately $1200-2000 \mu \mathrm{g} / \mathrm{mL}$ ), P. aeruginosa (MICs of approximately $800-2000 \mu \mathrm{g} / \mathrm{mL}$ ) and $S$. pyogenes (MICs of approximately 750-1300 $\mu \mathrm{g} / \mathrm{mL}$ ), the MIC values are still indicative of moderate to potent bacterial growth inhibition. Thus, the supercritical extracts (particularly the berry extract) have potential in the prevention and treatment of diseases associated with these bacteria.

\section{Anti-Giardial activity}

T. lanceolata extracts were also screened for their ability to inhibit Giardia duodenalis growth (Figure 6). In agreement with previous reports, ${ }^{14}$ the methanol and water extracts displayed particularly potent inhibitory activity, each completely blocking $G$. duodenalis proliferation (compared 


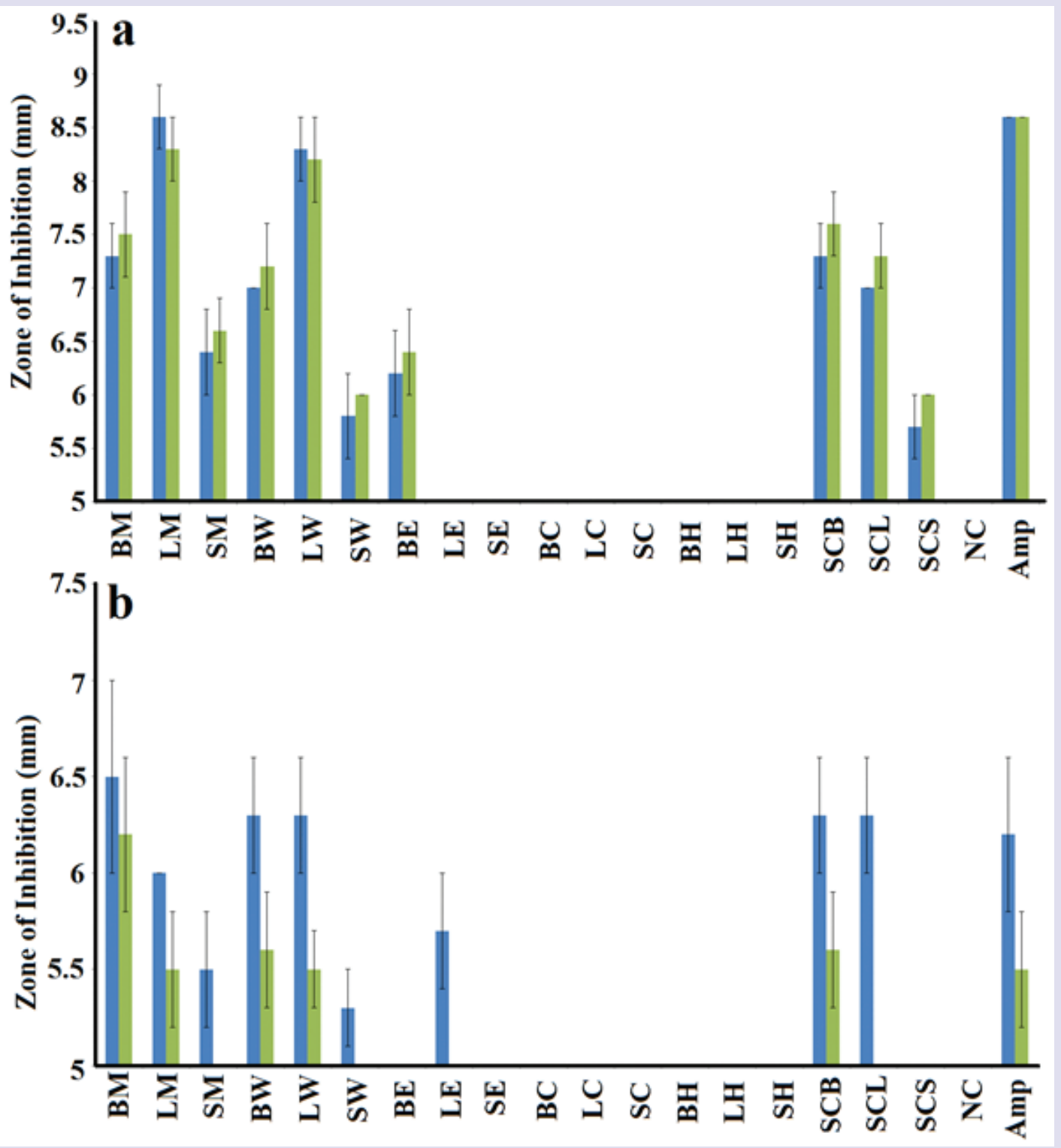

Figure 4: Antibacterial activity of $T$. lanceolata extracts measured as zones of inhibition $(\mathrm{mm})$ against a bacterial trigger of multiple sclerosis: (a) Acinitobacter baylyi, (b) Pseudomonas aeruginosa. Results are expressed as mean \pm SEM of at least triplicate determinations. Blue bars represent inhibition of the reference bacterial strain. Green bars represent inhibition of the clinical bacterial strain. $B M=$ methanolic berry extract; $L M=$ methanolic leaf extract; $S M=$ methanolic stem extract; $B W=$ aqueous berry extract; $L W=$ aqueous leaf extract; $S W=$ =aqueous stem extract; $B E=$ =ethyl acetate berry extract; $L E=e t h y l$ acetate leaf extract; $\mathrm{SE}=$ ethyl acetate stem extract; $\mathrm{BC}=$ =berry chloroform extract; $\mathrm{LC}=$ leaf chloroform extract; $\mathrm{SC}=$ stem chloroform extract; $\mathrm{BH}=$ berry hexane extract; $\mathrm{LH}=$ leaf hexane extract; $\mathrm{SH}=$ stem hexane extract; $\mathrm{SCB}=$ supercritical berry extract; $\mathrm{SCL}=$ supercritical leaf extract; $\mathrm{SCS}=$ supercritical stem extract; $\mathrm{NC}=$ negative control; $\mathrm{Amp}=$ ampicillin control $(10 \mu \mathrm{g})$.

to the untreated control). The ethyl acetate berry (100\% inhibition compared to the negative control), leaf ( $90 \%$ inhibition compared to the negative control) and stem extracts (71\% inhibition compared to the negative control) were also very effective at inhibiting trophozoite growth. The chloroform and hexane T. lanceolata extracts were less effective inhibitors of G. duodenalis proliferation. The berry and leaf chloroform extracts inhibited $65 \%$ and $35 \%$ of the G. duodenalis proliferation, respectively (compared to the untreated control). The berry, leaf and stem hexane extracts also significantly inhibited G. duodenalis proliferation by approximately $33 \%, 42 \%$ and $14 \%$, respectively. In comparison, all supercritical extracts were potent $G$. duodenalis inhibitors, each totally blocking proliferation.

The T. lanceolata extracts were further tested over a range of concentrations to determine the $\mathrm{IC}_{50}$ values (Table 3) for each extract against G. duodenalis. Inhibition of trophozoite growth was dose-dependent, with the level of inhibitory activity decreasing at lower concentrations. The small scale methanolic extracts were generally the most potent antiproliferative agents, with $\mathrm{IC}_{50}$ values of 194 and $175 \mu \mathrm{g} / \mathrm{mL}$ determined for the berry and leaf extracts, respectively. However, the aqueous and ethyl acetate extracts were also potent inhibitors of $G$. duodenalis 


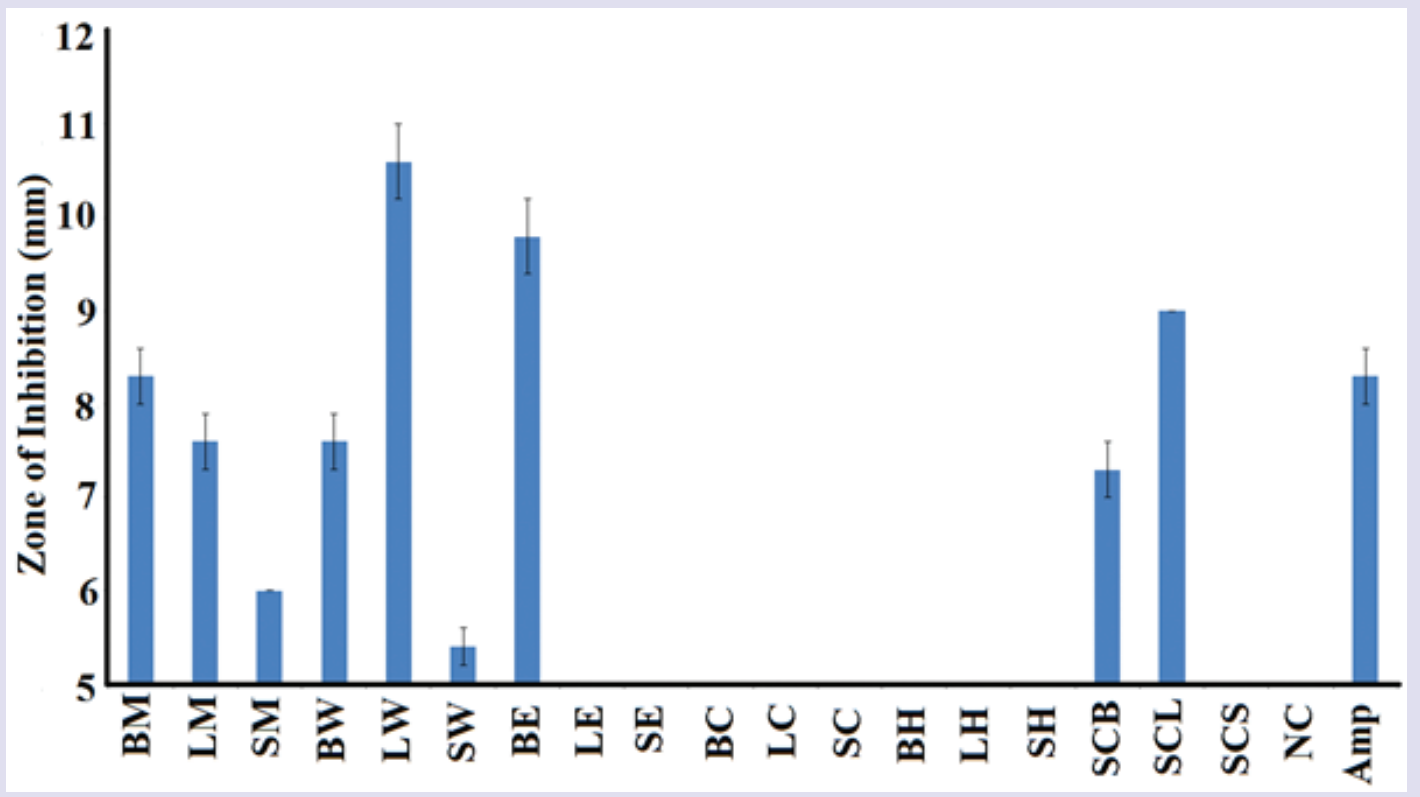

Figure 5: Antibacterial activity of T. lanceolata extracts measured as zones of inhibition $(\mathrm{mm})$ against a bacterial trigger of rheumatic fever (Streptococcus pyogenes). Results are expressed as mean \pm SEM of at least triplicate determinations. BM=methanolic berry extract; $\mathrm{LM}=$ methanolic leaf extract; $\mathrm{SM}=$ methanolic stem extract; $\mathrm{BW}=$ aqueous berry extract; $\mathrm{LW}=$ aqueous leaf extract; $\mathrm{SW}=$ aqueous stem extract; $\mathrm{BE}=$ ethyl acetate berry extract; $\mathrm{LE}=$ ethyl acetate leaf extract; $\mathrm{SE}=$ ethyl acetate stem extract; $\mathrm{BC}=$ berry chloroform extract; $\mathrm{LC}=$ leaf chloroform extract; $\mathrm{SC}=$ stem chloroform extract; $\mathrm{BH}=$ berry hexane extract; $\mathrm{LH}=$ leaf hexane extract; $\mathrm{SH}=$ stem hexane extract; $\mathrm{SCB}=$ supercritical berry extract; $\mathrm{SCL}=$ supercritical leaf extract; $\mathrm{SCS}=$ supercritical stem extract; $\mathrm{NC}=$ negative control; $\mathrm{Amp}=$ ampicillin control $(10 \mu \mathrm{g})$.

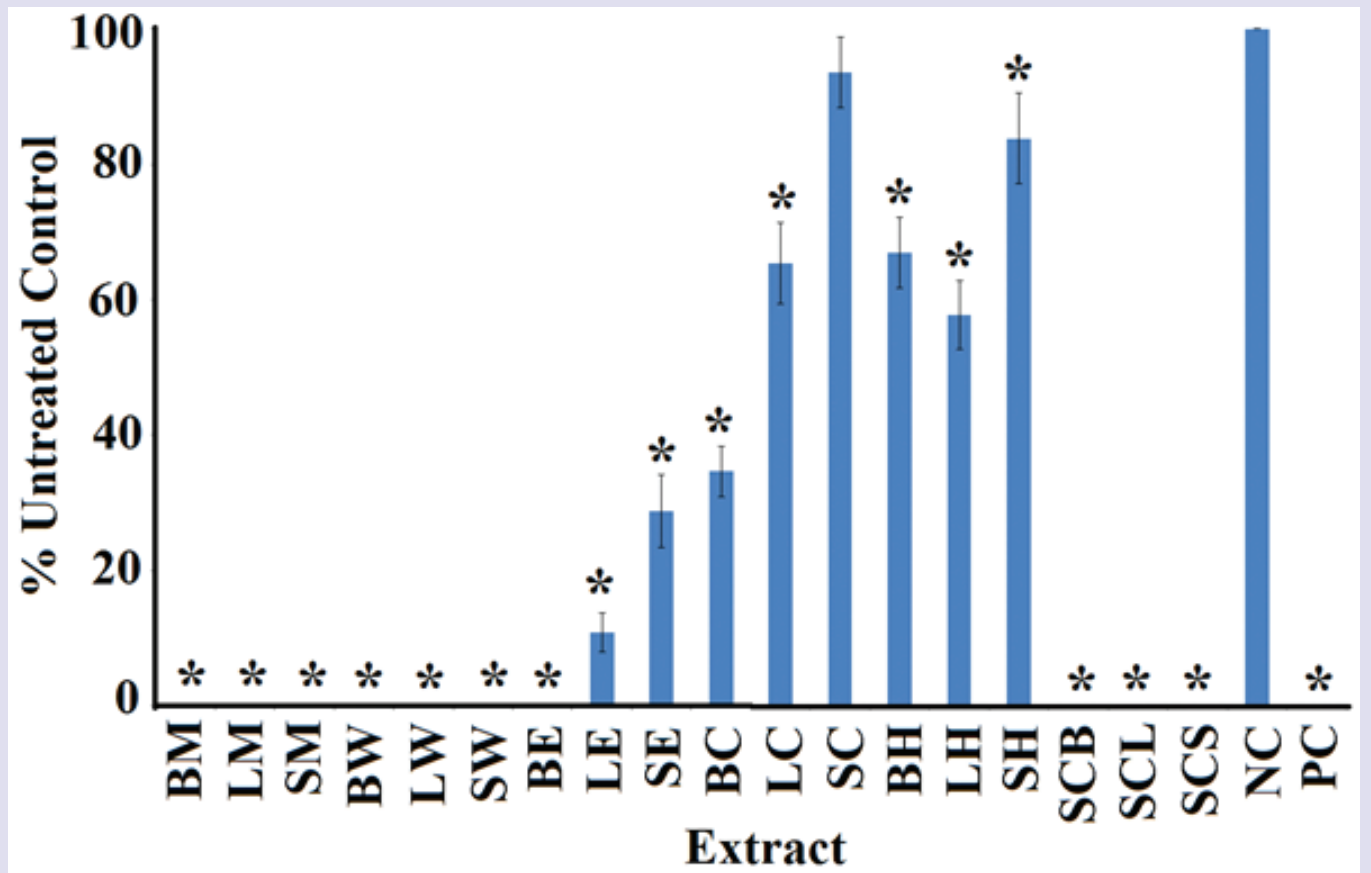

Figure 6: Inhibitory activity of $T$. lanceolata extracts against Giardia duodenalis trophozoites measured as a percentage of the untreated control. Results are expressed as mean \pm SEM of at least triplicate determinations. $B M=$ methanolic berry extract; $\mathrm{LM}=$ methanolic leaf extract; $\mathrm{SM}=$ methanolic stem extract; $\mathrm{BW}=$ aqueous berry extract; $\mathrm{LW}=$ aqueous leaf extract; $S W=$ aqueous stem extract; $\mathrm{BE}=$ ethyl acetate berry extract; $\mathrm{LE}=$ =thyl acetate leaf extract; $\mathrm{SE}=$ ethyl acetate stem extract; $\mathrm{BC}=$ berry chloroform extract; $\mathrm{LC}=$ leaf chloroform extract; $\mathrm{SC}=$ stem chloroform extract; $\mathrm{BH}=$ berry hexane extract; $\mathrm{LH}=$ leaf hexane extract; $\mathrm{SH}=$ stem hexane extract; $\mathrm{SCB}=$ supercritical berry extract; $\mathrm{SCL}=$ supercritical leaf extract; $\mathrm{SCS}=$ supercritical stem extract; $\mathrm{NC}=$ negative (seawater) control; $\mathrm{PC}=$ metronidazole control. ${ }^{*}$ indicates results that are significantly different to the negative control $(\mathrm{P}<0.01)$. 
proliferation, with $\mathrm{IC}_{50}$ values generally $<600 \mu \mathrm{g} / \mathrm{mL}$. The supercritical fluid extractions were similarly potent $G$. duodenalis inhibitors, with $\mathrm{IC}_{50}$ values of 492,375 and $883 \mu \mathrm{g} / \mathrm{mL}$ for the supercritical berry, leaf and stem extracts, respectively.

\section{Inhibition of cancer cell proliferation}

The T. lanceolata extracts were tested against 2 cancer cell lines ( $\mathrm{CaCo} 2$ colorectal carcinoma cells, Figure 7; HeLa cervical cancer cells, Figure 8) to determine their ability to inhibit cancer cell growth. The methanol and water extracts displayed potent inhibitory activity against $\mathrm{CaCo} 2$ cells, with proliferation inhibited to as low as approximately $1 \%$ of the untreated control cell growth for the methanolic berry extract (Figure 7). Indeed, all methanolic and aqueous extracts inhibited the growth by $>85 \%$ compared with the untreated control. The berry, leaf and stem ethyl acetate extracts were also effective at inhibiting $\mathrm{CaCo} 2$ proliferation (to approximately 44,48 and $89 \%$ of untreated cell proliferation respectively). Of the chloroform extracts, only the berry extract significantly inhibited $\mathrm{CaCo} 2$ proliferation. Interestingly, the hexane extracts not only did not inhibit $G$. duodenalis proliferation, but a significant stimulation of $\mathrm{CaCo} 2$ proliferation was noted. This is consistent with previous studies from our group which have reported similar growth stimulation for these extracts. ${ }^{4}$ The supercritical fluid extracts were also potent inhibitors of $\mathrm{CaCo} 2$ proliferation. The supercritical berry, leaf and stem extracts inhibited $\mathrm{CaCo} 2$ proliferation by 98,100 and $69 \%$, respectively.

The $T$. lanceolata extracts were also shown to affect the proliferation of HeLa cells (Figure 8). Whilst the extracts were potent inhibitors of HeLa proliferation, the inhibition was generally of lower efficacy than was evident with the $\mathrm{CaCo} 2$ cells. The methanol and water extracts were generally the most potent inhibitors of HeLa cells. The methanolic berry, leaf and stem extracts inhibited proliferation by 81,93 and $66 \%$, respectively. Similarly, the corresponding aqueous extracts inhibited HeLa proliferation by 93,96 and $78 \%$, respectively compared with the untreated control. The berry, leaf and stem ethyl acetate extracts were also potent inhibitors of HeLa cell proliferation (by approximately 72, 82 and 39\%, respectively compared to the untreated cell proliferation). Of the chloroform and hexane extracts, only the leaf extracts significantly inhibited HeLa proliferation (19 and 26\% inhibition, respectively compared to untreated control proliferation). Interestingly, the berry chloroform and hexane extracts not only did not inhibit HeLa proliferation, but a significant stimulation of cellular proliferation was noted. The supercritical fluid extracts were also potent inhibitors of HeLa proliferation. The supercritical berry, leaf and stem extracts inhibited HeLa proliferation by 100,100 and $73 \%$, respectively.

The T. lanceolata extracts were further tested over a range of concentrations to determine the $\mathrm{IC}_{50}$ values (Table 3) for each extract against $\mathrm{CaCo} 2$ and $\mathrm{HeLa}$ proliferation. Inhibition of proliferation was dosedependent for all extracts, with the level of inhibitory activity decreasing at lower concentrations (Table 3). The aqueous T. lanceolata leaf extract was a particularly potent anti-proliferative agent, with $\mathrm{IC}_{50}$ values of 150 and $230 \mu \mathrm{g} / \mathrm{mL}$ against $\mathrm{CaCo} 2$ and $\mathrm{HeLa}$ cells, respectively. The $\mathrm{IC}_{50}$ values calculated for all other small scale solvent extractions were generally $>1000 \mu \mathrm{g} / \mathrm{mL}$, indicating moderate anti-proliferative activity. Similarly, the $\mathrm{IC}_{50}$ values determined for the supercritical fluid extractions (2500$4000 \mu \mathrm{g} / \mathrm{mL}$ ) are in a similar range and are also indicative of moderate anti-proliferative activity.

\section{Quantification of toxicity}

T. lanceolata extracts were diluted to $4000 \mu \mathrm{g} / \mathrm{mL}$ (to give a bioassay concentration of $2000 \mu \mathrm{g} / \mathrm{mL}$ ) in artificial seawater for toxicity testing in the Artemia nauplii lethality bioassay. For comparison, the reference toxin potassium dichromate was also tested in the bioassay. Potassium dichromate was rapid in its induction of mortality, with mortality evident within 4 hours of exposure (unpublished results). All of the T. lanceolata extracts were slower at inducing mortality, with $\geq 12 \mathrm{hrs}$ needed for mortality induction. Despite the slower onset of mortality, the small scale solvent extractions induced mortality significantly above that of the artificial seawater control (Figure 9). Similarly, the supercritical fluid extractions induced similar mortality levels at $24 \mathrm{~h}$. To further evaluate the toxicity, each extract was tested across a range of concentrations in the Artemia nauplii bioassay. Table 3 shows the extract and control toxin concentrations required to achieve $50 \%$ mortality $\left(\mathrm{LC}_{50}\right)$ at various times. As toxicity of crude plant extracts has previously been defined as $24 \mathrm{LC}_{50}$ values $<1000 \mu \mathrm{g} / \mathrm{mL},{ }^{26}$ the measured $\mathrm{LC}_{50}$ values indicate that none of the small scale T. lanceolata solvent extractions were significantly toxic. Similarly, all of the supercritical extractions also had $\mathrm{LC}_{50}$ values substantially $>1000 \mu \mathrm{g} / \mathrm{mL}$ and were thus also deemed to be non-toxic.

\section{Non-targeted GC-MS headspace analysis of the $T$. lanceolata extracts}

As the methanolic T. lanceolata berry extract and the supercritical berry extract generally had the most potent bacterial growth inhibitory efficacy, anti-Giardial activity and carcinoma cell anti-proliferative activity (as determined by $\mathrm{MIC}$ and $\mathrm{IC}_{50}$; Table 3 ), they were deemed the most promising extracts for further phytochemical analysis. Optimised GC-MS parameters were developed and used to examine the phytochemical composition of these extracts. The resultant gas chromatograms are presented in Figures 10a and Figure 10b, respectively. Several marker compounds (polygodial, cineole, eugenol, linalool, terpineol) were selected as a comparison between the extracts as these have previously been reported to be present in relative abundance in T. lanceolata berry extracts. ${ }^{8,9}$ All of these compounds were detected in both the solvent extract and in the supercritical fluid extract. The major peak in both extracts eluted at approximately $16.4 \mathrm{~min}$. This compound was identified as linalool by database spectral comparison and by co-elution with an authentic standard. The relative abundance of this compound was nearly identical between the 2 extracts. Another major peak (identified as polygodial) was particularly evident in the methanolic extract at $20.9 \mathrm{~min}$ (Figure 10a). This compound was also identified in the supercritical berry extract. Whilst polygodial was still a major component in this extract, it is apparent that its relative abundance had decreased in the supercritical extract compared to the smaller scale solvent extract. Instead, the relative abundance of several other terpenoids has increased in the supercritical berry extract compared to the smaller scale methanolic berry extract. A large relative increase is evident for cineole (at $15.1 \mathrm{~min}$ ). Significant increases are also evident for terpineol (19.1 $\mathrm{min}$ ) and eugenol (23.8 $\mathrm{min})$. Thus, the overall composition between the 2 extracts appears to be similar although there is variation in the relative abundances of the selected marker compounds.

\section{DISCUSSION}

T. lanceolata berry and leaf extracts have been highlighted for their medicinal properties. Recent studies have reported berry extracts to have a high antioxidant capacity, ${ }^{4}$ as well as strong antibacterial activity, ${ }^{7-9,11}$ anti-inflammatory activity ${ }^{11}$ and anti-Giardial activity. ${ }^{14}$ The leaves also have high antioxidant contents, ${ }^{4-6}$ and are good inhibitors of bacterial growth..$^{7-9,11}$ Furthermore, T. lanceolata leaf extracts induce a reduction in pro-inflammatory enzymes in an inflammatory cell model ${ }^{10}$ and inhibit microbial triggers of several autoimmune inflammatory diseases. ${ }^{11}$ Leaf extracts have been reported to inhibit cellular proliferation in several carcinoma cell models, as well as inducing apoptosis in HepG2 cells. ${ }^{15}$ Similarly, T. lanceolata leaf extracts also block Giardia duodenalis proliferation and therefore have potential in the treatment of giardiasis. ${ }^{14}$ 


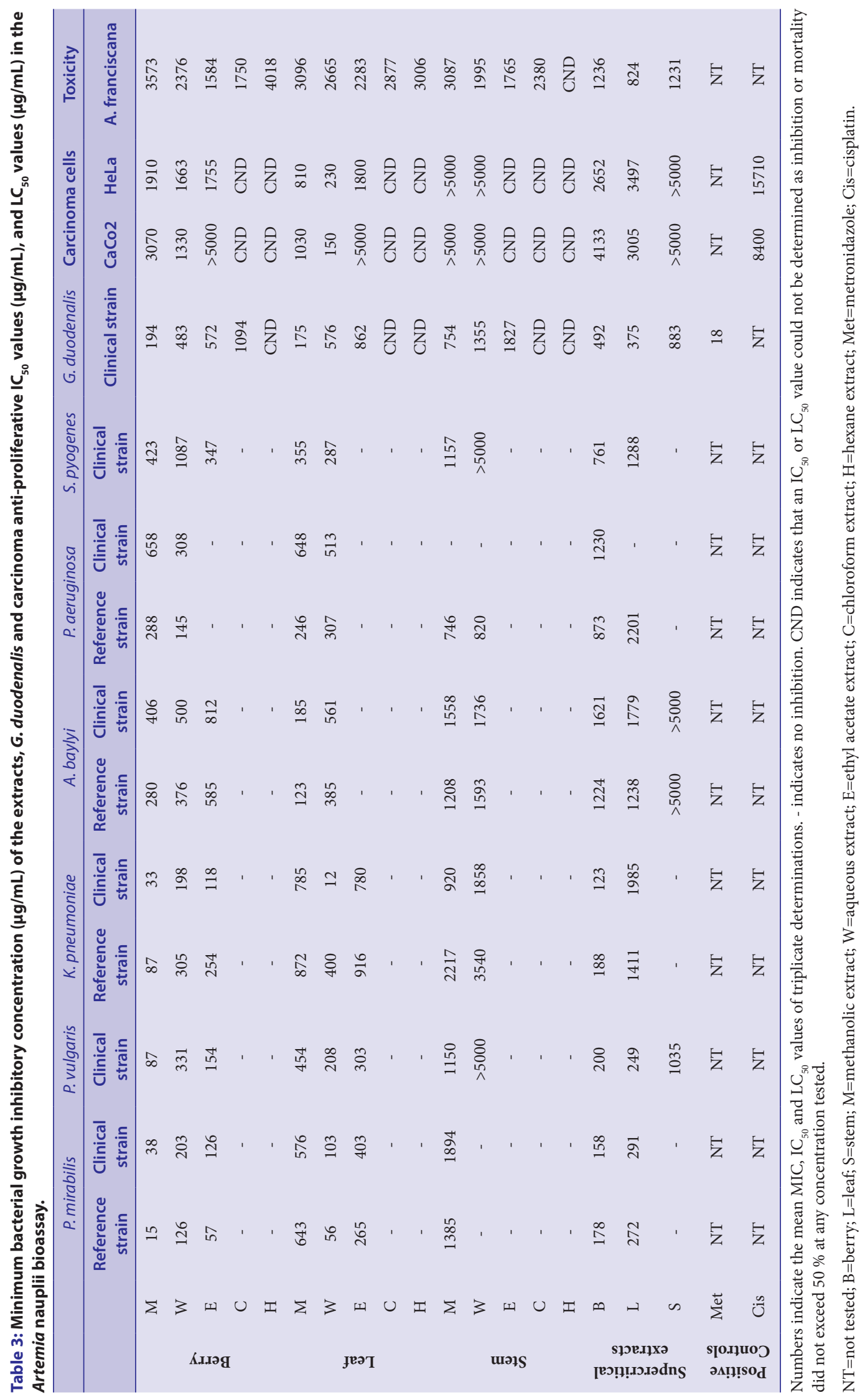




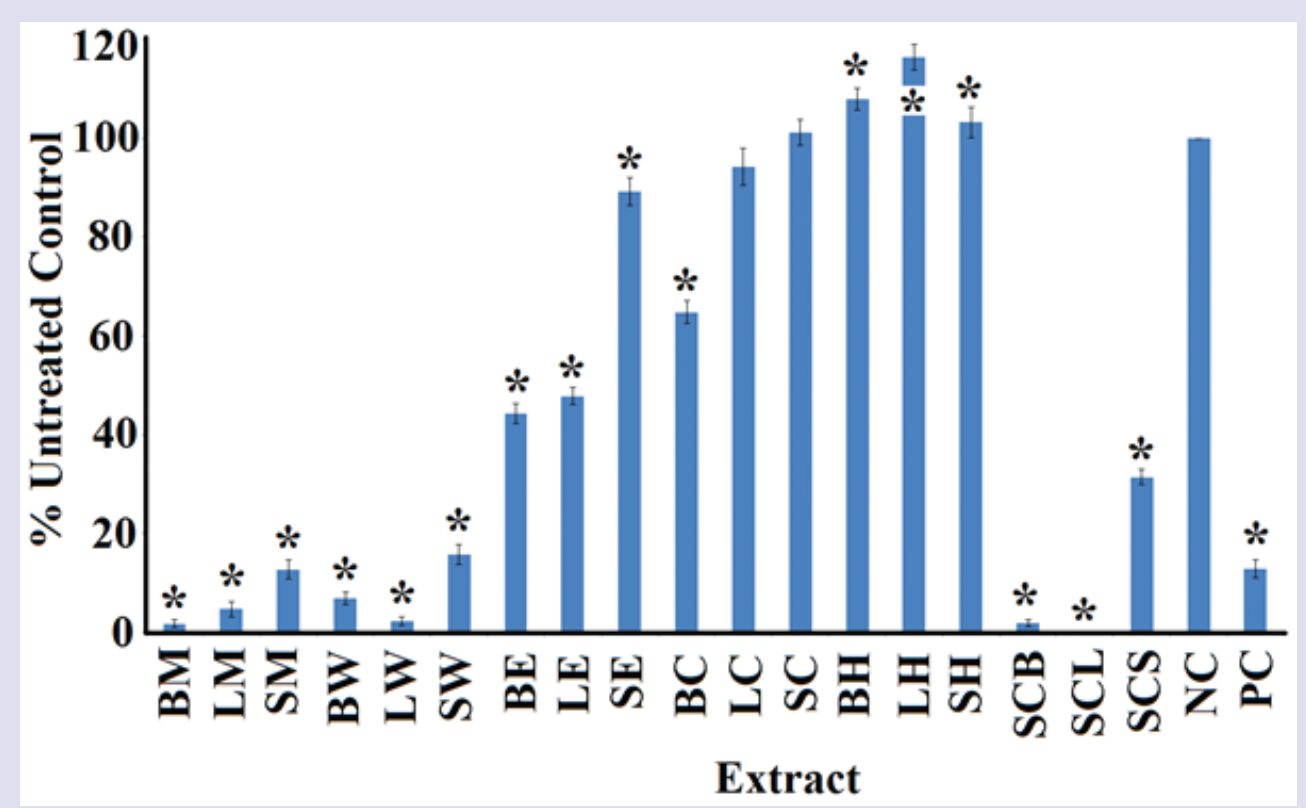

Figure 7: Anti-proliferative activity of T. lanceolata extracts and untreated controls against $\mathrm{CaCo} 2$ carcinoma cells measured as percentages of the untreated control cells. Results are expressed as mean percentages \pm SEM of at least triplicate determinations. $\mathrm{BM}=$ =methanolic berry extract; $\mathrm{LM}=$ methanolic leaf extract; $\mathrm{SM}=$ methanolic stem extract; $\mathrm{BW}=$ aqueous berry extract; $\mathrm{LW}=$ aqueous leaf extract; $S W=$ aqueous stem extract; $B E=$ ethyl acetate berry extract; $L E=$ ethyl acetate leaf extract; $S E=$ ethyl acetate stem extract; $\mathrm{BC}=$ berry chloroform extract; $\mathrm{LC}=$ =eaf chloroform extract; $\mathrm{SC}=$ stem chloroform extract; $\mathrm{BH}=$ berry hexane extract; $\mathrm{LH}=$ leaf hexane extract; $\mathrm{SH}=$ stem hexane extract; $\mathrm{SCB}=$ supercritical berry extract; $\mathrm{SCL}=$ supercritical leaf extract; $\mathrm{SCS}=$ supercritical stem extract; $\mathrm{NC}=$ negative $\left(\right.$ seawater) control; $\mathrm{PC}=$ cisplatin control $(50 \mathrm{mg} / \mathrm{mL}) .{ }^{*}$ indicates results that are significantly different to the negative control $(\mathrm{P}<0.01)$.

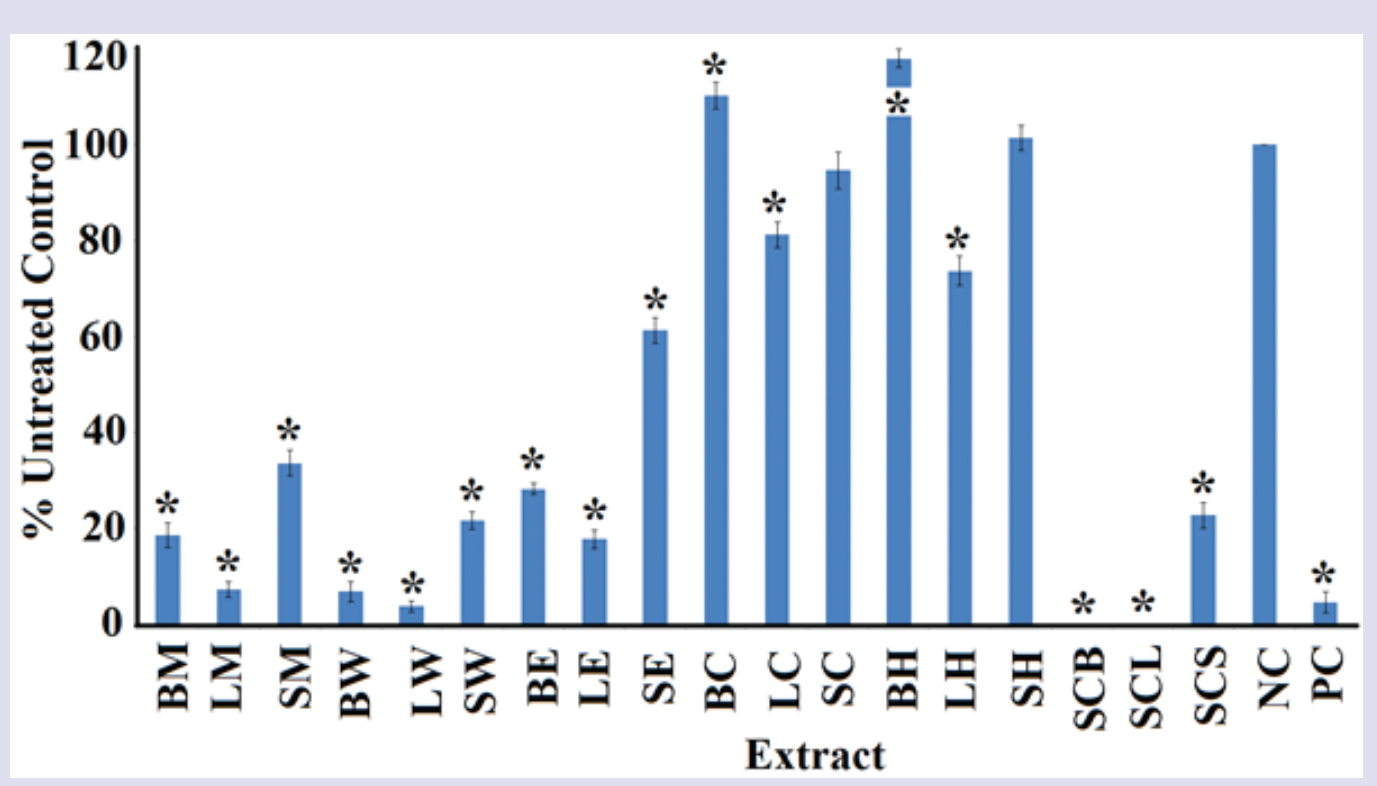

Figure 8: Anti-proliferative activity of $T$. lanceolata extracts and untreated controls against HeLa carcinoma cells measured as percentages of the untreated control cells. Results are expressed as mean percentages \pm SEM of at least triplicate determinations. $\mathrm{BM}=$ methanolic berry extract; $\mathrm{LM}=$ methanolic leaf extract; $\mathrm{SM}=$ methanolic stem extract; $\mathrm{BW}=$ aqueous berry extract; $\mathrm{LW}=$ aqueous leaf extract; $\mathrm{SW}=$ aqueous stem extract; $\mathrm{BE}=$ ethyl acetate berry extract; $\mathrm{LE}=$ ethyl acetate leaf extract; $\mathrm{SE}=$ ethyl acetate stem extract; $\mathrm{BC}=$ berry chloroform extract; $\mathrm{LC}=$ leaf chloroform extract; $\mathrm{SC}=$ stem chloroform extract; $\mathrm{BH}=$ berry hexane extract; $\mathrm{LH}=$ leaf hexane extract; $\mathrm{SH}=$ stem hexane extract; $\mathrm{SCB}=$ supercritical berry extract; $\mathrm{SCL}=$ supercritical leaf extract; $\mathrm{SCS}=$ supercritical stem extract; $\mathrm{NC}=$ negative (seawater) control; $\mathrm{PC}=$ cisplatin control $(50 \mathrm{mg} / \mathrm{mL})$. * indicates results that are significantly different to the negative control $(\mathrm{P}<0.01)$. 


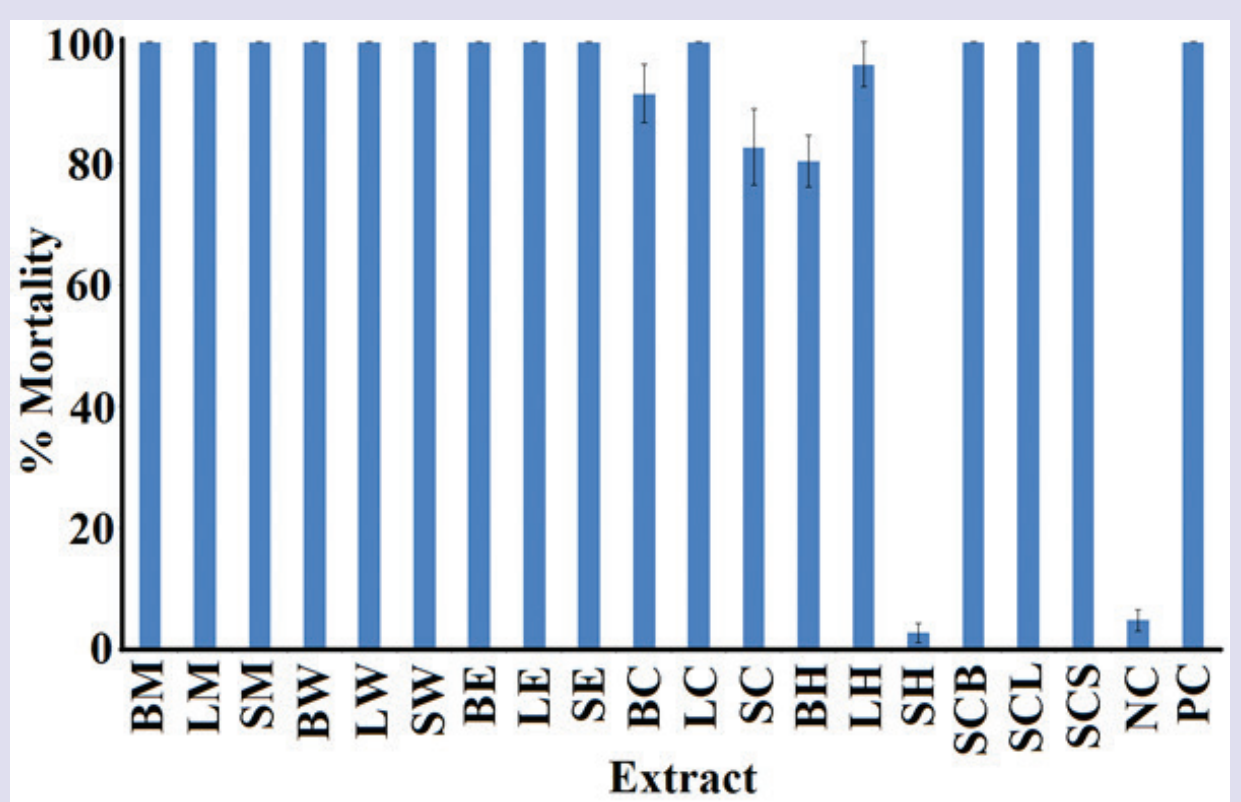

Figure 9: The lethality of $T$. lanceolata extracts and potassium dichromate $(1000 \mu \mathrm{g} / \mathrm{mL})$ and artificial seawater controls towards Artemia franciscana nauplii after $24 \mathrm{hrs}$ exposure. Results are expressed as mean \pm SEM of at least triplicate determinations. $\mathrm{BM}=$ methanolic berry extract; $\mathrm{LM}=$ methanolic leaf extract; $\mathrm{SM}=$ methanolic stem extract; $\mathrm{BW}=$ aqueous berry extract; $\mathrm{LW}=$ aqueous leaf extract; $\mathrm{SW}=$ aqueous stem extract; $\mathrm{BE}=$ ethyl acetate berry extract; $\mathrm{LE}=$ ethyl acetate leaf extract; $\mathrm{SE}=$ ethyl acetate stem extract; $\mathrm{BC}=\quad$ berry chloroform extract; $\mathrm{LC}=$ leaf chloroform extract; $\mathrm{SC}=$ stem chloroform extract; $\mathrm{BH}=$ berry hexane extract; $\mathrm{LH}=$ leaf hexane extract; $\mathrm{SH}=$ stem hexane extract; $\mathrm{SCB}=$ supercritical berry extract; $\mathrm{SCL}=$ supercritical leaf extract; $\mathrm{SCS}=$ supercritical stem extract; $\mathrm{NC}=$ negative (seawater) control; $\mathrm{PC}=$ potassium dichromate control.
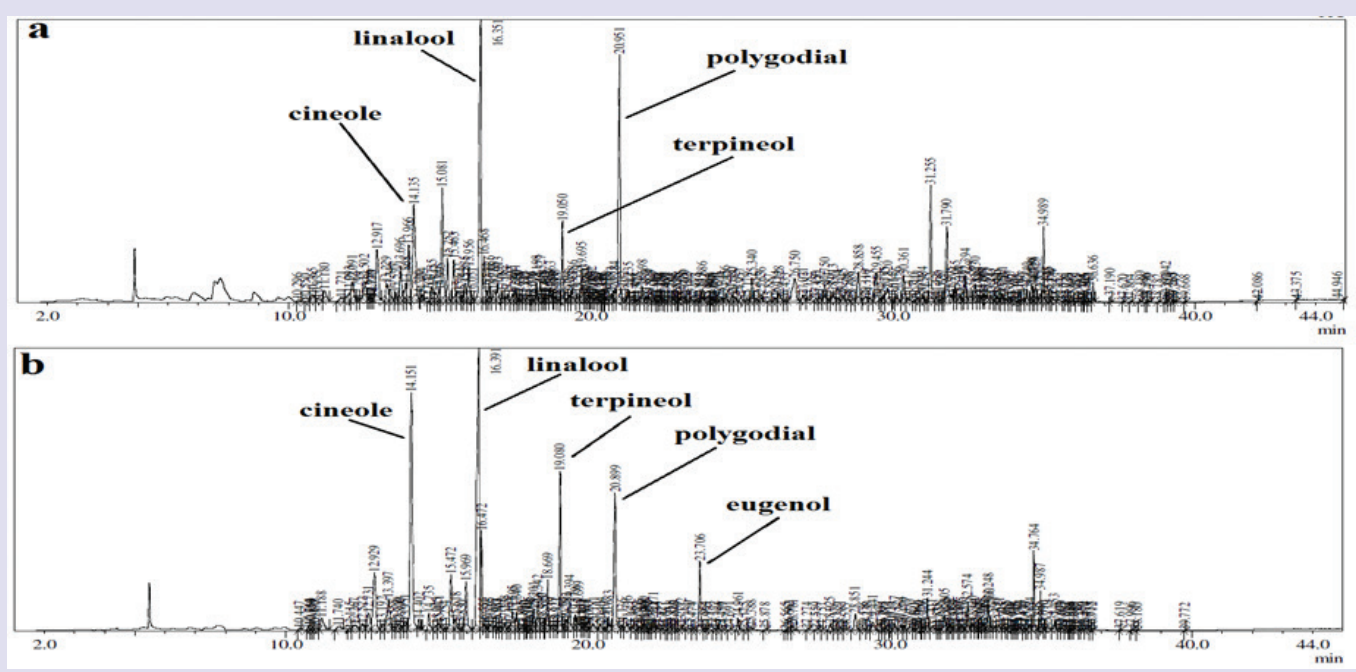

Figure 10: Head space gas chromatogram of $0.5 \mu \mathrm{L}$ injections of $T$. lanceolata berry (a) methanolic extract and (b) supercritical berry extract. The extracts were dried and resuspended in methanol. Major phytochemical components are identified as a comparison between the extraction methods.

However, it is noteworthy that all of these studies utilised small scale laboratory extraction methodologies to prepare extracts for biological screening. Despite numerous promising reports of therapeutic properties, we were unable to find any studies which report methods to scale up the extraction to commercially relevant levels.

The aim of this study was to develop a quick and simple extraction method which would allow the extraction of substantially increased masses of plant material without significantly affecting the quality of the extract produced. Supercritical fluid extraction (SFE) was selected for the development of an extraction protocol as it has several advantages over other methods:

- Supercritical fluids (SF) have similar solvating powers to liquid organic solvents but higher diffusivities, lower viscosities and lower surface tension. 
- Alteration of the temperature and pressure conditions can readily be adjusted, allowing for rapid separation of analytes.

- The polarity of the SF can readily be modified to provide more selective separation.

- The extracts produced by SFE do not have residual solvent present (as may be the case in solvent extraction protocols). This is extremely favourable for extracts with pharmaceutical or food uses.

- Diffusivities are much faster in SFs than in liquid solvents. Therefore SFE is substantially more rapid than liquid solvent extraction. Less time is required to produce large amounts of extract using SFE.

- Substantially less costly solvent is used than for liquid solvent extraction. As well as decreasing processing costs, this results in significant reductions in drying time and substantially less environmental risk due to solvent pollution.

With consideration of these potential benefits, ethanol dimethyl ether based SFE protocol was developed and trialled. As previous studies have reported the therapeutic potential of the berry and leaves, these plant materials were both extracted using our SFE protocol and tested in parallel with extracts produced by liquid solvent extraction. As an extension of these studies, we also extracted T. lanceolata stem and twig material by both SFE and liquid solvent extraction techniques. A variety of bioassay systems were selected for bioactivity screening. These tests were chosen to give the broadest possible understanding of the therapeutic properties of the extracts. All extracts were screened for the ability to inhibit the growth of bacterial species that are triggers for autoimmune inflammatory diseases as these would not only provide insight into the ability to block bacterial growth as well as indicating therapeutic options in some inflammatory diseases. The extracts were also screened to for the ability to inhibit the growth of the eukaryotic pathogen G. duodenalis and the carcinoma cell lines $\mathrm{CaCo} 2$ and HeLa.

A thorough literature search was unable to find any previous studies examining the therapeutic properties of $T$. lanceolata stem and twig material. This is perhaps surprising as the properties of berry, leaf and peppercorn have been extensively reported previously. The stem material is a by-product of current harvesting methods and is generally considered of little value. It was believed that if the stem material was found to have therapeutic properties similar to those reported for the berry and leaf, then this 'waste material' may be repurposed for the production of therapeutic agents. Interestingly, the stem extracts did have notable therapeutic properties. In particular, the methanolic and aqueous stem extracts inhibited the growth of most bacterial species, with MIC values in the range $750-2000 \mu \mathrm{g} / \mathrm{mL}$. These values indicate moderate to good growth inhibitory activity. Thus the aqueous and methanolic stem extracts have potential in the prevention and treatment of rheumatoid arthritis, ankylosing spondylitis, multiple sclerosis and rheumatic fever. However, despite this promising finding, it is noteworthy that these MIC values indicate that the stem extracts are 1-2 orders of magnitude less potent that the corresponding berry and leaf extracts. For example, the MIC of the methanolic stem extract towards the reference $P$. mirabilis strain $(1385 \mu \mathrm{g} / \mathrm{mL})$ is approximately 100 times less potent than the methanolic berry extract against the same bacterium $(15 \mu \mathrm{g} / \mathrm{mL})$. Good anti-Giardial $\mathrm{IC}_{50}$ values were also determined for the methanolic stem extract $(754 \mu \mathrm{g} / \mathrm{mL})$. However, this extract was also a considerably less potent inhibitor of $G$. duodenalis proliferation than the corresponding berry and leaf methanolic extracts (194 and $175 \mu \mathrm{g} / \mathrm{mL}$, respectively).

Screening the supercritical berry and leaf extracts for therapeutic properties demonstrated that both had potent antibacterial properties with similar efficacies to the smaller scale liquid solvent extractions. The MIC values of the supercritical berry and leaf extracts against most bacterial species were $<1000 \mu \mathrm{g} / \mathrm{mL}$, indicating the potential of these extracts in the prevention and treatment of some autoimmune inflammatory diseases. The MIC values of the supercritical berry extract against P. mirabilis (178 and $158 \mu \mathrm{g} / \mathrm{mL}$ against reference and clinical strains, respectively) and $K$. pneumoniae (200 and $188 \mu \mathrm{g} / \mathrm{mL}$ against reference and clinical strains, respectively) indicate that these extracts may be especially useful for the prevention of rheumatoid arthritis and ankylosing spondylitis. The supercritical berry and leaf extracts also had similar anti-proliferative potencies against $G$. duodenalis, $\mathrm{CaCo} 2$ and $\mathrm{HeLa}$ carcinomas to those determined for the corresponding liquid solvent extractions. Thus, whilst the supercritical extraction method used in these studies resulted in a far greater extraction throughput as well as reduced extraction time and costs, the resultant supercritical extracts retained therapeutic activities at or near the potency of the smaller scale liquid solvent extracts. Furthermore, toxicity screening in the Artemia nauplii bioassay indicate that the berry and stem supercritical extracts are non-toxic with $\mathrm{LC}_{50}$ values $>1000 \mu \mathrm{g} / \mathrm{mL}$. Whilst an $\mathrm{LC}_{50}$ value $<1000$ $\mu \mathrm{g} / \mathrm{mL}$ was determined for the supercritical leaf extract, this value indicates only low toxicity. The A. franciscana assay is sensitive to extreme $\mathrm{pH}$ ranges and samples with high phenolic acid contents may adversely alter the $\mathrm{pH}$. Thus, it is possible that the apparent toxicity reported in this study is a fallacious result due to the high phenolic acid content of the extracts and these are in fact non-toxic. Thus, SFE can produce substantially greater masses of extracted material with similar therapeutic potential as the smaller liquid solvent extraction techniques.

A comparison of the phytochemical composition of the liquid solvent extracts and the supercritical fluid extracts was used as a further quality control measure. Several important terpenoids were selected for this study on the basis of their known bioactivities relevant to the therapeutic properties tested in this study, and reports of their relevant abundance in T. lanceolata extracts. ${ }^{8,9}$ The selected terpenoids have been previously reported to have potent broad spectrum antibacterial activity ${ }^{1}$ and therefore are likely to contribute to the inhibitory activity reported in this study. Furthermore, these terpenoids have also been reported to suppress NF- $\kappa B$ signalling (the major regulator of inflammatory diseases) and are thus likely to contribute to the anticancer and anti-inflammatory properties of T. lanceolata. ${ }^{30-33}$ Minor changes in phytochemical abundance were evident between the extracts produced by the different methods. A higher relative abundance of polygodial was evident in the berry methanolic extract produced by liquid solvent extraction compared to the relative abundance in the supercritical berry extract. Conversely, the supercritical berry extract had correspondingly greater abundance of cineole, terpineol and eugenol. The relative abundance of linalool was consistent between the extracts.

Whilst this study provides insight into the phytochemical compositions of the T. lanceolata extracts, it is noteworthy that no single technique will detect and identify all compounds responsible for any therapeutic property in an extract. Our study utilised a GC-MS headspace technique to examine the extracts. This technique was chosen as the biomarker compounds are known to be detected using these techniques. ${ }^{8,9}$ As detection of volatile, relatively nonpolar compounds is suited to GC-MS headspace analysis, this was an appropriate analytical tool for detecting terpenoids components. However, these extracts are likely to contain many more polar compounds that were not detected in this study. Indeed, several previous studies utilising LC-MS analysis have highlighted the phytochemical complexity of $T$. lanceolata extracts. Thus, whilst extraction by SFE techniques does not appear to have resulted in dramatic changes in phytochemical composition (at least for the volatile lower polarity compounds), further studies using LC-MS analysis are required to ensure that more dramatic differences between the extracts are not apparent with respect to their polar components. 


\section{CONCLUSION}

The results of this study demonstrate that supercritical fluid extraction is a viable method of extraction of large masses of T. lanceolata plant material rapidly and with high yields. Similarly, the supercritical extracts generally retain their therapeutic properties, are non-toxic and have similar profiles and abundances of several therapeutically important terpenoids as smaller scale liquid solvent extractions.

\section{ACKNOWLEDGEMENTS}

Financial support for this work was provided by the Environmental Futures Research Institute and the School of Natural Sciences, Griffith University.

\section{CONFLICT OF INTEREST}

The authors report no conflicts of interest.

\section{ABBREVIATION USED}

DMSO: Dimethyl sulfoxide

IC50: The concentration required to achieve a $50 \%$ reduction in activity LC50: The concentration required to achieve $50 \%$ mortality

MIC: minimum inhibitory concentration

\section{REFERENCES}

1. Cock IE. The phytochemistry and chemotherapeutic potential of Tasmania lanceolata (Tasmanian pepper): A review. Pharmacognosy Communications. 2013:3(4):1-13. DOI: 10.5530/pc.2013.4.3

2. Cock IE. Medicinal and aromatic plants - Australia, in Ethnopharmacology section, Biological, Physiological and Health Sciences, Encyclopedia of Life Support Systems (EOLSS), 2011; Developed under the Auspices of the UNESCO, EOLSS Publishers, Oxford, UK, (http://www.eolss.net).

3. Lassak EV, McCarthy T. Australian Medicinal Plants. A complete guide to identification and usage. Reed New Holland Publishers 2011, Sydney Australia.

4. Jamieson N, Sirdaarta J, Cock IE. The anti-proliferative properties of Australian plants with high antioxidant capacities against cancer cell lines. Pharmacognosy Communications. 2014;4(4):71-82. DOI: 10.5530/pc.2014.4.8

5. Konczak I, Zabaras D, Dunstan M. Antioxidant capacity and phenolic compounds in commercially grown native Australian herbs and spices. Food Chemistry. 2010;122(1):260-6.

6. Netzel M, Netzel G, Tian Q. Native Australian fruits-a novel source of antioxidants for food. Innovative Food Science and Emerging Technology 2007:8(3):339-46

7. Winnett $\mathrm{V}$, Boyer $\mathrm{H}$, Sirdaarta J, et al. The potential of Tasmannia lanceolata as a natural preservative and medicinal agent: Antimicrobial activity and toxicity. Pharmacognosy Communications. 2014;4(1):42-2. DOI: 10.5530/pc.2014.1.7

8. Wright MH, Matthews B, Greene AC, et al. Metabolomic profiling of polar Tasmannia lanceolata extracts shown to inhibit Bacillus anthracis growth. Pharmacognosy Communications 2016. In press.

9. Wright MH, Lee CJ, Arnold MSJ, et al. GC-MS analysis of Tasmannia lanceolata extracts which inhibit the growth of the pathogenic bacterium Clostridium perfringens. Phytochemical analysis 2016. In press.

10. Guo Yu, Sakulnarmrat K, Konczak I. Anti-inflammatory potential of native Australian herbs polyphenols. Toxicology Reports. 2014;1:385-90.

11. Cock IE, Winnett $V$, Sirdaarta J. The potential of selected Australian medicinal plants with anti-Proteus activity for the treatment and prevention of rheumatoid arthritis. Pharmacognosy Magazine. 2015;42(Supp1):S190-S208. DOI: 10.4103/0973-1296.157734
12. Cock IE. The early stages of rheumatoid arthritis: New targets for the development of combinational drug therapies. OA Arthritis. 2014;2(1):5.

13. Cock IE. van Vuuren SF. The potential of selected South African plants with antiKlebsiella activity for the treatment and prevention of ankylosing spondylitis. Inflammopharmacology. 2015;23(1):21-35. DOI: 10.1007/s10787-014-0222-z

14. Rayan P, Matthews B, McDonnell PA, et al. Phytochemical analysis of Tasmannia lanceolata extracts which inhibit Giardia duodenalis proliferation. Pharmacognosy Journal. 2016;8(3):291-9. DOI : 10.5530/pj.2016.3.19.

15. Sakulnarmrat K, Fenech M, Thomas P. Cytoprotective and pro-apoptotic activities of native Australian herbs polyphenolic-rich extracts. Food Chemistry. 2013; 136(1):9-17.

16. Menary RC. Mountain pepper extract, Tasmannia lanceolata: quality stabilisation and registration. A report for the Rural Industries Research and Development Corporation (RIRDC). Barton ACT.; 2003. (http://www.rirdc.gov.au/reports/ EOl/02-148.pdf.

17. Kalt FR, Cock IE. Gas chromatography-mass spectroscopy analysis of bioactive Petalostigma extracts: Toxicity, antibacterial and antiviral activities. Pharmacog nosy Magazine. 2014;10(37 Supp):S37-S49. DOI: 10.4103/0973-1296.127338

18. Sautron C, Cock IE. Antimicrobial activity and toxicity of Syzygium australe and Syzygium leuhmannii fruit extracts. Pharmacognosy Communications. 2014;4(1):53-60. DOI: 10.5530/pc.2014.1.8

19. Vesoul J, Cock IE. The potential of Bunya nut extracts as antibacterial functional foods. Pharmacognosy Communications. 2012;2(1):72-9. DOI: 10.5530/ pc.2012.1.13

20. Vesoul J, Cock IE. An examination of the medicinal potential of Pittosporum phylliraeoides: toxicity, antibacterial and antifungal activities. Pharmacognosy Communications. 2011;1(2):8-17. DOI: 10.5530/pc.2011.2.3

21. Arkhipov A, Sirdaarta J, Rayan $P$, et al. An examination of the antibacterial, antifungal, anti-Giardial and anticancer properties of Kigelia africana fruit extracts. Pharmacognosy Communications. 2014;4(3):62-76. DOI: 10.5530/pc.2014.3.7

22. Hart C, Ilanko P, Sirdaarta J, et al. Tasmannia stipitata as a functional food/natural preservative: Antimicrobial activity and toxicity. Pharmacognosy Communications. 2014;4(4):33-47. DOI: 10.5530/pc.2014.4.4

23. Courtney R, Sirdaarta J, Matthews B, etal.Tannin components and inhibitory activity of Kakadu plum leaf extracts against microbial triggers of autoimmune inflammatory diseases. Pharmacognosy Journal. 2015;7(1):18-31. DOI: 10.5530/ pj.2015.7.2

24. Cock IE. Assessment of the toxicity of selected Australian native plant extracts using the Artemia franciscana nauplii bioassay. Internet Journal of Toxicology. 2008;5:2

25. Ruebhart DR, Wikramasinghe WA Cock IE. Protective efficacy of the antioxidants vitamin $\mathrm{E}$ and Trolox against Microcystis aeruginosa and microcystin-LR in Artemia franciscana nauplii. Journal of Toxicology and Environmental Health Part A. 2009;72(24):1567-75.

26. Cock IE, Ruebhart DR. Comparison of the brine shrimp nauplii bioassay and the ToxScreen-II test for the detection of toxicity associated with Aloe vera (Aloe barbadensis Miller) leaf extract. Pharmacognosy Research. 2009;1(2):98-101.

27. Biggs I, Sirdaarta J, White A, et al. GC-MS analysis of frankincense extracts which inhibit the growth of bacterial triggers of selected autoimmune diseases. Pharmacognosy Communications. 2015;6(1):10-22. DOI: 10.5530/pc.2016.1.3

28. Ebringer $A$, Hughes $L$, Rashid T. Acinetobacter immune response in multiple sclerosis. Etiopathogenetic role and its possible use as a diagnostic marker. JAMA Neurology. 2005;62(1):33-6.

29. Rashid T, Ebringer A. Autoimmunity in rheumatic diseases is induced by microbial infections via cross reactivity or molecular mimicry. Autoimmune Disease. 2012;Article ID 539282. DOI: 10.1155/2012/539282.

30. Salminen A, Lehtonen M, Suuronen T. Terpenoids: Natural inhibitorsof NF- $\kappa B$ signalling with anti-inflammatory and anticancer potential. Cellular and Molecular Life Sciences. 2008;65(19):2979-99.

31. Lu XG, Zhan LB, Feng BA. Inhibition of growth and metastasis ofhuman gastric cancer implanted in nude mice by d-limonene. World Journal of Gastroenterology. 2004;10(14):2140-4.

32. Zhou JY, Tang FD, Mao GG. Effect of a-pinene on nucleartranslocation of NF-kB in THP-1 cells. Acta Pharmacologica Sinica. 2004;25(4):480-4.

33. Crowell PL. Prevention and therapy of cancer by dietary monoterpenes. Journal of Nutrition. 1999:129(3):775S-8S 
PICTORIAL ABSTRACT

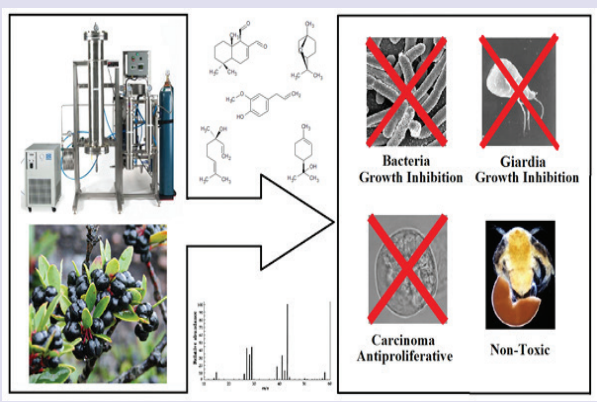

\section{SUMMARY}

- T. lanceolata berry and leaf SFEs displayed strong bacterial growth inhibitory activity against bacterial triggers of autoimmune inflammatory diseases.

- The SFEs had similar efficacies to the smaller scale liquid solvent extractions.

- The SFE also had similar antiproliferative potencies against $G$. duodenalis, $\mathrm{CaCo} 2$ and HeLa carcinomas to the solvent extractions.

- GC-MS analysis revealed similar terpenoid components and similar abundances between the SFEs and the solvent extractions.

- All SFEs were either non-toxic or of only low toxicity in the Artemia franciscana toxicity assay.

\section{ABOUT AUTHORS}

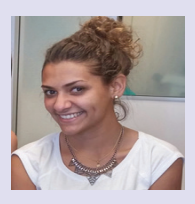

Ms Low Vallette is a postgraduate student at School of Biology, Ecole de Biologie Industrielle (EBI), Cergy, France. In 2015, she undertook a research project in Dr lan Cock's laboratory in the School of Natural Sciences at Griffith University examining the therapeutic properties of a variety of Australian native plants.

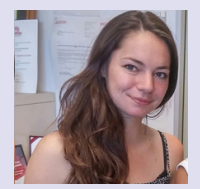

Ms Camille Rabadeaux is a postgraduate student at School of Biology, Ecole de Biologie Industrielle (EBI), Cergy, France. In 2015, she undertook a research project in Dr lan Cock's laboratory in the School of Natural Sciences at Griffith University examining the therapeutic properties of a variety of Australian native plants.

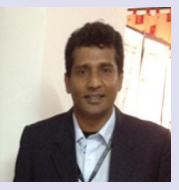

Joseph Sirdaarta is currently a PhD student at School of Natural Sciences, Griffith University, Australia under the supervision of Dr lan Cock. His research project examinines the anticancer properties of a variety of Australian native plants. He has also undertaken studies into antibacterial, antiprotozoal and anti-inflammatory properties of natural and traditional medicines, resulting in over 20 publications and 15 conference presentations.

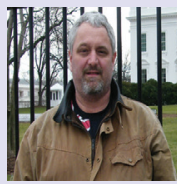

Dr lan Cock leads a research team in the Environmental Futures Research Institute and the School of Natural Sciences at Griffith University, Australia. His research involves bioactivity and phytochemical studies into a variety of plant species of both Australian and international origin, including Aloe vera, South Asian and South American tropical fruits, as well as Australia plants including Scaevola spinescens, Pittosporum phylliraeoides, Terminalia ferdinandiana (Kakadu plum), Australian Acacias, Syzygiums, Petalostigmas and Xanthorrhoea johnsonii (grass trees). This range of projects has resulted in nearly 200 publications in a variety of peer reviewed journals. 